\section{LA PUNTA DE MUESCA \\ DE TIPO MEDITERRÁNEO: ANÁLISIS TECNOLÓGICO Y FUNCIONAL}

\author{
THE SHOULDERED POINT OF THE \\ MEDITERRANEAN TYPE: FUNCTIONAL \\ AND TECHNOLOGICAL ANALYSIS
}

FRANCISCO J. MUÑOZ IBÁÑEZ (*)

\section{RESUMEN}

En este trabajo se aborda el estudio de las puntas de muesca de tipo mediterráneo, procedentes del yacimiento solutrense de La Cueva de Ambrosio (Vélez Blanco, Almería) y que se encuadran en el Solutrense Superior Evolucionado. Este tipo de proyectiles se caracterizan a partir de parámetros morfológicos y tipométricos. Asimismo, se propone un modelo teórico sobre los procesos de fabricación y su repercusión en el registro arqueológico. Por último, el análisis exhaustivo de estas puntas de proyectil permite establecer algunas hipótesis sobre su funcionalidad en relación a los sistemas de engaste y de propulsión.

\begin{abstract}
This paper deals with the study of the shouldered point of mediterranean type, coming from the Upper Evolved Solutrean levels of "La Cueva de Ambrosio" (Almería, Spain). This type of proyectile points are characterized from morphological and typometrical parameters. A theoretical model is also proposed to explain the manufacturing processes and their effect on the archaeological record. Finally, the exhaustive analysis of these arrowheads makes it possible to establish some hypotheses on the functioning of their set systems and propulsion systems.
\end{abstract}

(*) Becario de F.P.I. del Departamento de Prehistoria e $\mathrm{H}^{\mathrm{a}}$ Antigua de la Universidad Nacional de Educación a Distancia. Avda. Senda del Rey, s/n. 28071 Madrid. Correo electrónico: fmunoz@sr.uned.es.

El artículo fue remitido en su versión final el 14-XI-96.
Palabras clave: Punta de muesca de tipo mediterráneo. Tecnología lítica. Solutrense Superior Evolucionado. Sureste español.

Key words: Shouldered point of the mediterranean type. Lithic technology. Upper Evolved Solutrean. Southeastern Spain.

\section{INTRODUCCIÓN}

En la secuencia del Paleolítico Superior de la vertiente mediterránea el Solutrense es una industria bien conocida e individualizada desde el punto de vista material, artístico, climático y cronocultural. Sin embargo, aquellos elementos más característicos de esta cultura y que marcan un cambio fundamental y radical con respecto a momentos anteriores, las puntas líticas de proyectil, no han sido objeto de un estudio detallado.

Debido a la gran extensión del levante peninsular, el trabajo se centrará en la Andalucía Oriental, donde se ubica el yacimiento de estudio -La Cueva de Ambrosio-, y el País Valenciano, donde se encuentran las estaciones más representativas de este periodo para establecer paralelos y comparaciones (Fig. 1).

En Parpalló y Mallaetes, que poseen estratigrafías para los inicios de este período, los nive- 


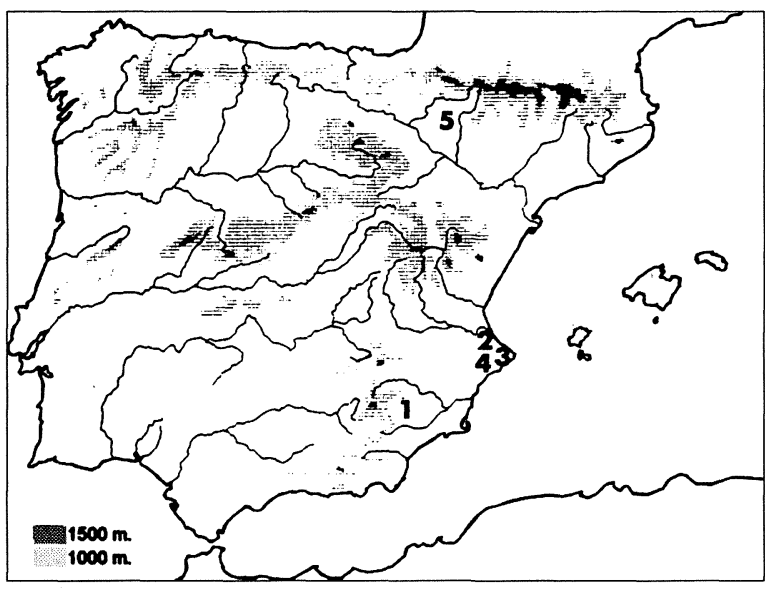

Fig. 1. Mapa de dispersión de los yacimientos citados en el texto. 1: La Cueva de Ambrosio (VélezBlanco, Almería); 2. Cova del Parpalló (Gandía, Valencia); 3: Les Mallaetes (Bárig, Valencia); 4: Barranc Blanc (Rotova, Valencia); 5: Cueva de Chaves (Bastaras, Huesca).

les pertenecientes al Solutrense Inferior y Medio marcan un cambio fundamental y radical con respecto a las etapas anteriores. En el País Valenciano, tras un gravetiense bien individualizado, el Solutrense Inferior se ha caracterizado por la presencia de puntas de cara plana y la casi total ausencia de elementos con retoque abrupto (gravettes, microgravettes y hojitas de dorso). El segundo rasgo más relevante es la preeminencia de los raspadores sobre los buriles.

En la siguiente etapa, el Solutrense Medio, hay una ocupación más intensa y consolidada, ampliándose el número de yacimientos en la región valenciana (Barranc Blanc) y extendiéndose al ámbito andaluz (Ambrosio, Los Ojos, Nerja). Las series industriales muestran la continuidad de las puntas de cara plana y la aparición de las primeras puntas foliáceas que van sustituyendo a las primeras. Por otro lado, se mantiene el predominio de los raspadores sobre los buriles. Al final de esta fase surgen las primeras puntas de proyectil pedunculadas (Parpalló y Ambrosio).

El Solutrense Superior está integrado por las hojas de laurel. Todavía aparece de forma esporádica alguna punta de cara plana, y surgen por primera vez las puntas de muesca con retoque abrupto. Esta etapa se caracteriza por el predominio de las puntas de aletas y pedúnculo. Sus peculiaridades tecnológicas y morfológicas les con- fieren un altísima rentabilidad cinegética, como demuestra el hecho de la perduración de este morfotipo como punta de proyectil hasta la actualidad. Es ahora cuando este tipo de punta se extiende al resto de las áreas solutrenses de la península, exceptuando la cornisa cantábrica. A partir de esta etapa y en la siguiente, se observa una extensión del fenómeno solutrense hacia el sur y el oeste, llegando hasta la provincia de Cádiz, como lo atestiguan los materiales de Cuevas de Levante y Cubeta de la Paja.

El Solutrense Superior Evolucionado es la última etapa de esta cultura en la región mediterránea. En el utillaje característico del grupo solutrense hay una progresiva desaparición del retoque plano invasor, que es desplazado por la importancia del retoque abrupto representado, fundamentalmente, por las hojitas de dorso y por las puntas de muesca. En el final de esta etapa desciende el índice de escotaduras y asciende la industria ósea en general y, en particular, los proyectiles óseos. Estos cambios parecen documentar un proceso de lenta adaptación condicionada por el sustrato regional.

Quedan esbozados así los principales rasgos y la evolución interna del Solutrense en la región valenciana y el SE peninsular.

En cuanto al yacimiento de La Cueva de Ambrosio (Fig. 1), se encuentra situado en la comarca de Los Vélez (Vélez Blanco, Almería). En esta zona, el oeste de Almería, aparecen los relieves calizos más desarrollados. Esta región montañosa limita al norte con los llanos de Caravaca de la Cruz (Murcia) y, al sur, con las ramblas de Nogalte y Chirivel, vía de comunicación natural que une la zona costera del Levante y la Andalucía continental. Se sitúa, pues, en uno de los pasos obligados para acceder a la costa desde el interior y viceversa. Además, tiene una localización privilegiada, en la cabecera de un valle, lo que $a$ priori dota a este hábitat de gran interés para actividades cinegéticas.

La Cueva de Ambrosio es propiamente un gran abrigo abierto en un farallón de calizas miocénicas, de casi $100 \mathrm{~m}$. de altura. Actualmente, la cavidad se encuentra parcialmente rellena de sedimentos. Así, se atestigua una ocupación que abarca desde el Solutrense (Niveles VI, IV y II) hasta la Edad del Bronce (Ripoll, 1988).

Este artículo se centrará en las puntas de muesca de tipo mediterráneo del Nivel II. Su industria se encuadra en un Solutrense Superior

T. P., 54, n. ${ }^{\circ} 1,1997$ 
Evolucionado con una datación de $16.500 \pm 280$ B.P. (Gif. 7275). El Grupo Solutrense (G.S. $21,71 \%)$ mantiene unos porcentajes muy elevados, sumando 133 piezas. Las puntas de muesca representan casi la mitad del Grupo Solutrense $(44,36 \%)$. La elección de este morfotipo ha estado condicionada en gran medida por ser la punta de proyectil más característica y numerosa del Solutrense Superior Evolucionado. Las 57 piezas de la muestra proceden de las campañas de excavación efectuadas durante 1990 y 1992. Éstas se centraron fundamentalmente en el Nivel II, por lo que las puntas de muesca recuperadas del Nivel IV (Solutrense Superior) fueron muy escasas (cuatro ejemplares). Así, no se han podido comparar las de uno y otro nivel, ya que el resultado habría estado distorsionado y carecería de validez.

\section{LA PUNTA DE MUESCA DE TIPO MEDITERRÁNEO}

A pesar del interés que desde antiguo han despertado las industrias solutrenses $y$, por ende, su utillaje característico, no se ha creado una metodología propia para el estudio de las puntas líticas de proyectil. Asimismo, no hay unos parámetros generalizados para la comparación de colecciones y las correlaciones entre diferentes conjuntos suelen basarse en datos tipométricos y tipológicos, más que en datos tecnológicos y funcionales. Las metodologías propuestas (Ripoll, 1960-1961; Rasilla, 1981; Straus, 1983) normalmente adolecían de una recogida rigurosa de datos o bien eran demasiado simplistas. No obstante, hay que destacar los trabajos de Geneste y Plisson (1986 y 1990; Plisson y Geneste, 1989) sobre las puntas de muesca solutrenses del sur de Francia.

Debido a la escasa atención que las listas tipológicas prestan al grupo solutrense, ninguna de las clasificaciones tipológicas existentes sirven para la definición y caracterización del morfotipo de la denominada punta de muesca de ámbito mediterráneo. Ésta quedaría incluida dentro del $n^{\circ} 70$ de la lista-tipo de Sonneville-Bordes, que se corresponde con el amplio mundo de las "armaduras mediterráneas". No obstante, subsiste el problema de su individualización del resto de las armaduras ligeras. En el ámbito europeo diversos trabajos sobre proyec- tiles muy similares (Lenoir, 1975; Onoratini, 1978; Bietti, 1980; Broglio et alii, 1993) han centrado su atención más sobre su diversidad morfológica que sobre su definición. Para el levante español, el único trabajo monográfico de referencia (Villaverde y Peña, 1981) sigue las mismas pautas de los arriba citados, sus resultados son meramente descriptivos y adolece de una documentación exhaustiva.

Ante estas circunstancias, parece oportuno mantener la denominación de "punta de muesca mediterránea" (Ripoll, 1988) para este tipo de proyectil, que anteriormente se identificaba como "levantina" o "parpallense". La nomenclatura de punta de muesca mediterránea tendría su razón de ser por el ámbito geográfico en donde aparece: región valenciana, Murcia y Andalucía Oriental, aunque recientemente han aparecido algunos ejemplares en el valle del Ebro (Utrilla y Mazo, 1994). Constituye un elemento característico del final del Solutrense en el levante peninsular y, por tanto, con un valor cronológico intrínseco siempre que esté asociado a otros útiles solutrenses bifaciales, ya que este tipo de proyectiles se han documentado en contextos mesolítico y eneolíticos (Martí y Gil, 1978; Pla, 1978). Esta punta se define por su retoque abrupto muy localizado en el dorso y a veces en el borde opuesto. El pedúnculo está formado por una muesca generalmente con retoque también abrupto. En algunas ocasiones la pieza tiene un retoque simple en el otro borde.

Este tipo de proyectil sería el equivalente de la punta de muesca solutrense de retoque plano, las puntas más numerosas y características del Solutrense Final francés. Están realizadas sobre una hoja generalmente corta, estrecha y plana. El retoque invasor, por presión, forma la punta. La muesca se realiza en el extremo proximal con un retoque más abrupto. La longitud y anchura del soporte disminuye muy poco durante el proceso de talla (Fig. 2).

Otro elemento de polémica y confusión es la terminología para definir si el pedúnculo está formado por una muesca o una escotadura. El empleo de "punta de muesca" o "punta escotada", según de que investigador se trate, hace referencia al mismo concepto. Esta duplicidad de términos no tendría mayor importancia si previamente quedara definida y aclarada, por lo que parece conveniente pronunciarse sobre el tema. La confusión arranca de la traducción al 

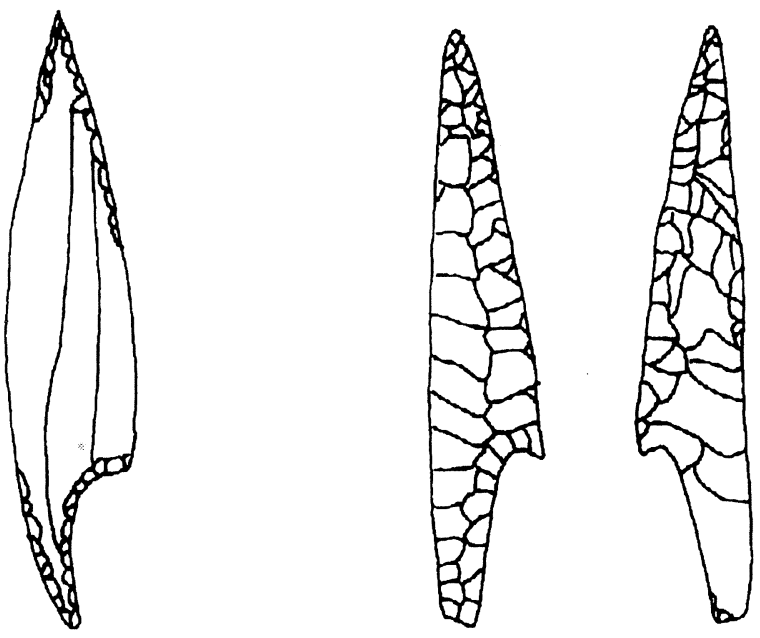

1

2

Fig. 2. Puntas de muesca del Solutrense. 1: Punta de muesca de tipo mediterráneo procedente de la Cueva de Ambrosio (Vélez-Blanco, Almería) hallada por Federico de Motos. 2: Punta de muesca solutrense de retoque plano del Solutrense Final de la región de la Dordoña (Francia).

castellano de los términos franceses "cran" y "encoche". Algunos autores (Moure, 1969; Fortea, 1973; Fullola, 1976; Villaverde y Peña, 1981) traducen el término "cran" como escotadura y "encoche" como muesca, mientras que otros investigadores (Ripoll, 1998; Merino, 1994) lo interpretan a la inversa. Para los primeros, el término "cran" lleva implícita una posición predeterminada en el soporte -proximal derecha-, mientras que "encoche" no implica una ubicación espacial precisa. Sin embargo, para los otros autores la traducción sería la opuesta. $\mathrm{Si}$ se admite la primera alternativa, nos encontramos con puntas cuya escotadura se presenta en el lado izquierdo o en el extremo distal. Sin embargo, siguiendo su propia argumentación, para definir con propiedad este tipo de proyectil habría que hablar de punta de muesca; ya que ésta última no tiene una posición predeterminada en el soporte y puede aparecer en el extremo distal o proximal y en su lado derecho o izquierdo. Esto parece tener más coherencia, desde el punto de vista semántico, si se admite el término de punta de muesca mediterránea, que es el adoptado en este trabajo.

\section{Materia prima}

Todas las puntas de proyectil están elaboradas sobre sílex. En un primer examen macroscópico, el $56 \%$ de la muestra tiene como soporte un sílex criptocristalino, mientras que el $44 \%$ se realiza sobre un sílex jaspeado. Estos porcentajes demuestran que no hay una predeterminación en la elección de una variedad de sílex concreta. Parece confirmarse que las numerosas fuentes de materia prima detectadas en el área de captación del yacimiento son bastante aptas para la tallar laminar (Fig. 3: A). Éste sería el principal condiciona-
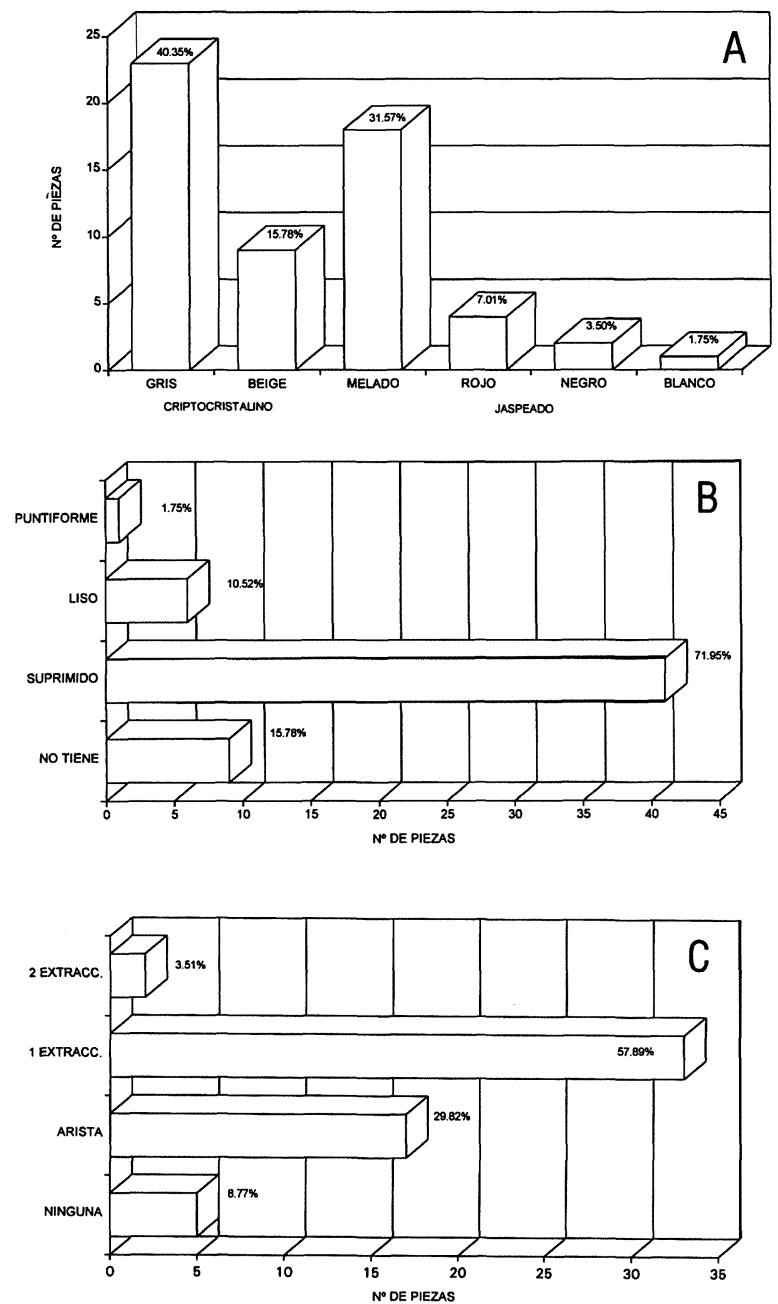

Fig. 3. Puntas de muesca de tipo mediterráneo del Solutrense Superior Evolucionado (Cueva Ambrosio, Vélez-Blanco, Almería). A: Subtipos de materia prima; B: Tipos de talones; C. Extracciones previas del soporte. 
miento para escoger un determinado tipo de materia prima sobre otro, ya que el retoque abrupto por presión en el filo del soporte no plantearía grandes problemas de ejecución. Esto apuntaría a un rendimiento similar para la consecución de los soportes característicos, así como unas condiciones de obtención y transporte parejas.

El $21 \%$ de la muestra presenta impurezas en la superficie externa del soporte. Normalmente son de pequeño tamaño y no parece que tengan gran incidencia en el proceso de transformación. En todos los casos aparecen en los subtipos de color gris o beige, fundamentalmente en el primero. En ninguna de las puntas se han observado fisuras que pudieran influir negativamente durante su elaboración o uso. En cuanto a las alteraciones, únicamente el 7\% de las piezas están desilificadas. Este porcentaje se reparte de forma homogénea entre el sílex de color gris, beige y melado. La relativa abundancia de materia prima permite lograr productos sin impurezas o alteraciones que distorsionen su comportamiento mecánico durante los procesos de obtención y transformación del soporte.

\section{Soporte}

Una característica inherente a la punta de muesca mediterránea es su elaboración sobre soportes laminares. En la muestra, el 78,96\% de los soportes son hojas y el 19,29\% son hojitas. Un solo ejemplar estaba realizado sobre un soporte sin características tecnológicas que lo definieran (Fig. 4: 25). Los útiles sobre hojita que conservan su longitud total se aproximan casi siempre a los $20 \mathrm{~mm}$., barrera teórica que separa la categoría de hoja y hojita.

Las hojas y hojitas en su inmensa mayoría tienen el talón suprimido por el retoque, seguidas porcentualmente de las que no tienen talón, debido fundamentalmente a las fracturas (Fig. 3: B). Tan sólo en siete proyectiles se pueden individualizar dos tipos: liso y puntiforme. Esto indica que no hay una preparación previa para destacar el punto de impacto de la superficie de percusión. La supresión del talón no debe entenderse tan solo como una fase dentro del proceso de elaboración-realizar la muesca-, ya que en tal caso el talón quedaría solo parcialmente eliminado. El otro objetivo es suprimir la zona bulbar para garantizar un enmangue óptimo cuando la muesca se realiza en este punto y, conseguir un reverso lo más regular posible que asegure una mayor penetración, cuando el bulbo coincide con el extremo distal del proyectil. La media aritmética del espesor del talón es de $3 \mathrm{~mm}$., cuando se conserva y se sitúa en la zona de la muesca, mientras que para toda la muestra dicha medida es de 1,88 . Así, varía tan solo algo más de un milímetro. Cuando el talón se sitúa en el extremo distal de la punta de muesca su espesor es de $2 \mathrm{~mm}$. y siempre se trata de proyectiles cuyo proceso de elaboración no se ha completado (Fig. 5: 3). Es decir, cuando se elige el talón para realizar el extremo distal del proyectil, aquél no sobrepasa un espesor determinado ( $2 \mathrm{~mm}$.).

No obstante, la mayoría de las veces la muesca se efectúa en la zona del talón (61\%). En el $23 \%$ de los casos no ha sido posible identificar su posición y en un $16 \%$ se sitúa en la punta. Estos porcentajes se refieren a toda la muestra de estudio, no solamente a las puntas que conservan el talón. Cuando éste falta, en la mayoría de las ocasiones su ubicación dentro del soporte se ha reconocido a partir de las ondas de percusión. Estos porcentajes parecen lógicos si se desea conseguir la mayor rentabilidad posible de la morfología que brinda el soporte. Así, el extremo proximal de la hoja tiene un mayor grosor, lo que facilita conseguir una muesca suficientemente espesa para asegurar un enmangue resistente y, al mismo tiempo, sin un espesor grande para dificultar su sujeción al astil. Por otro lado, el extremo distal de la hoja, si no tiene accidentes de talla como el reflejado, permite obtener una punta y un filo cortante con una escasa elaboración. $\mathrm{La}$ existencia de soportes reflejados puede obligar al tallador a optar por hacer la muesca en el extremo distal de la hoja al tener mayor grosor que la zona bulbar.

Los accidentes de talla de los soportes son de dos tipos: sobrepasado (33,33\%) (Fig. 5: 6) y torsión (5,6\%) (Fig. 6: 6). Parece lógica la existencia de un cierto número de soportes sobrepasados, si se tiene en cuenta la técnica de talla empleada: muy probablemente percusión indirecta o presión. La longitud total de las puntas sobrepasadas se sitúa, en la mayoría de los casos, entre los 25 y los $30 \mathrm{~mm}$. Considerando que la media aritmética para todo el conjunto es de $31,03 \mathrm{~mm}$., la reducción de la longitud del soporte para eliminar este accidente de talla conllevaría la obtención de proyectiles demasiado peque- 

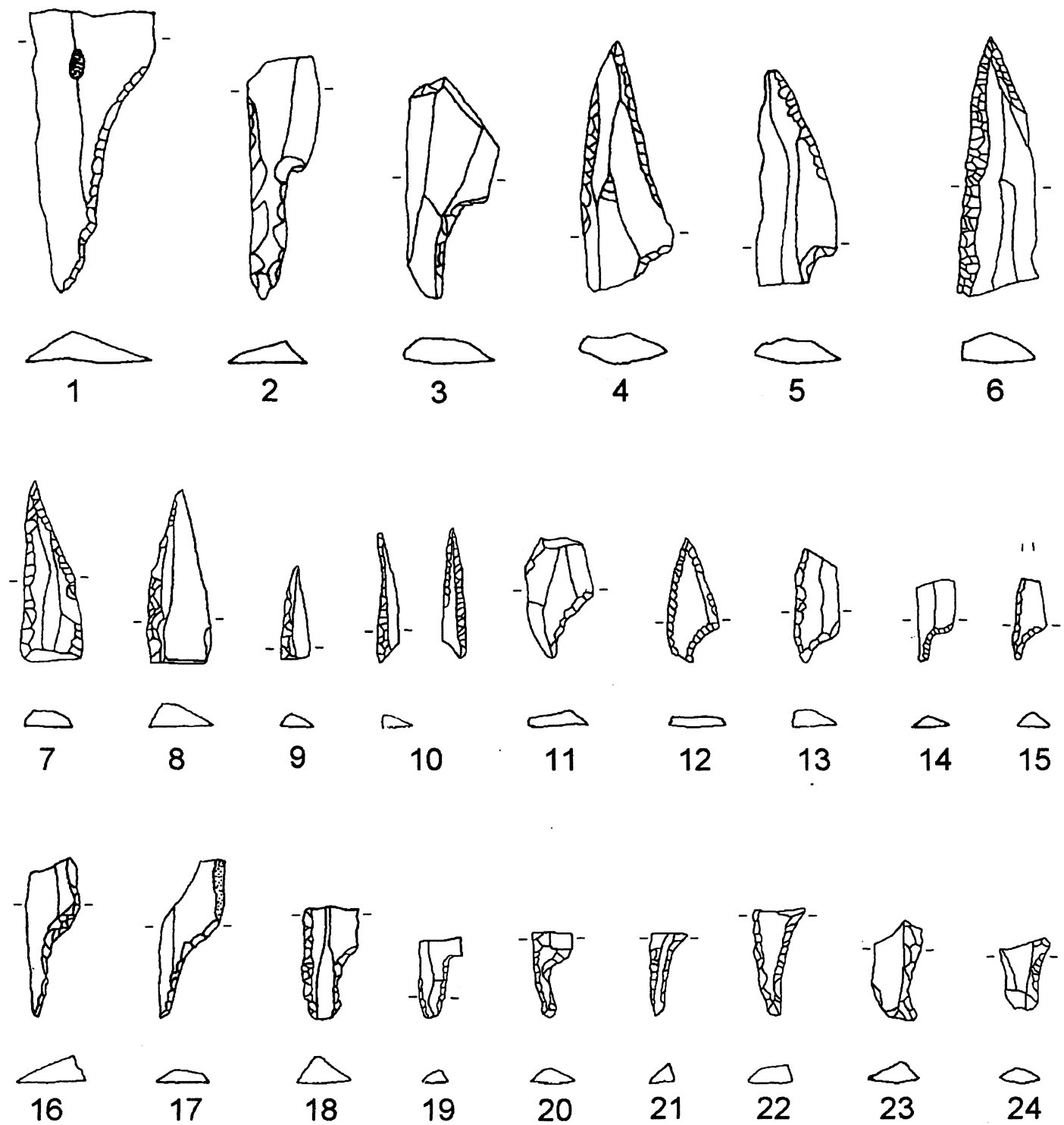

$\frac{\Delta}{19}$

$\curvearrowright$

$\underset{21}{\Delta} \gtrsim_{22}$

$\sum_{23}$

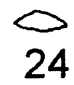
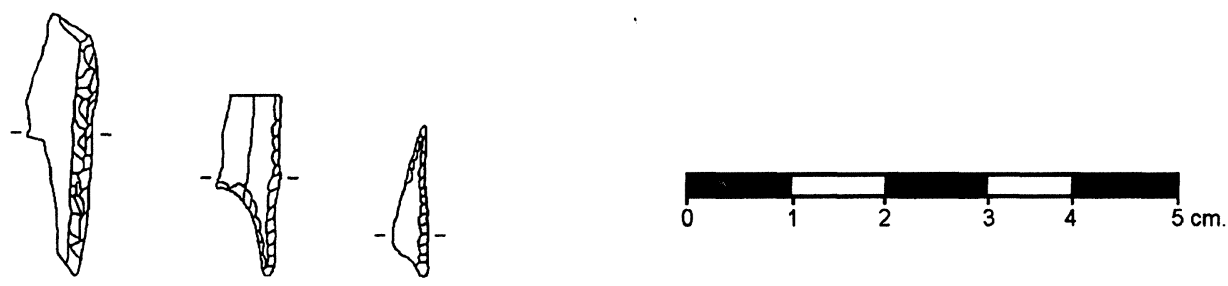

$\gtrsim_{25} \underset{26}{\Delta} \quad \Delta$

Fig. 4. Puntas de muesca de tipo mediterráneo. La Cueva de Ambrosio (Vélez-Blanco, Almería): Solutrense Superior Evolucionado (Nivel II). 

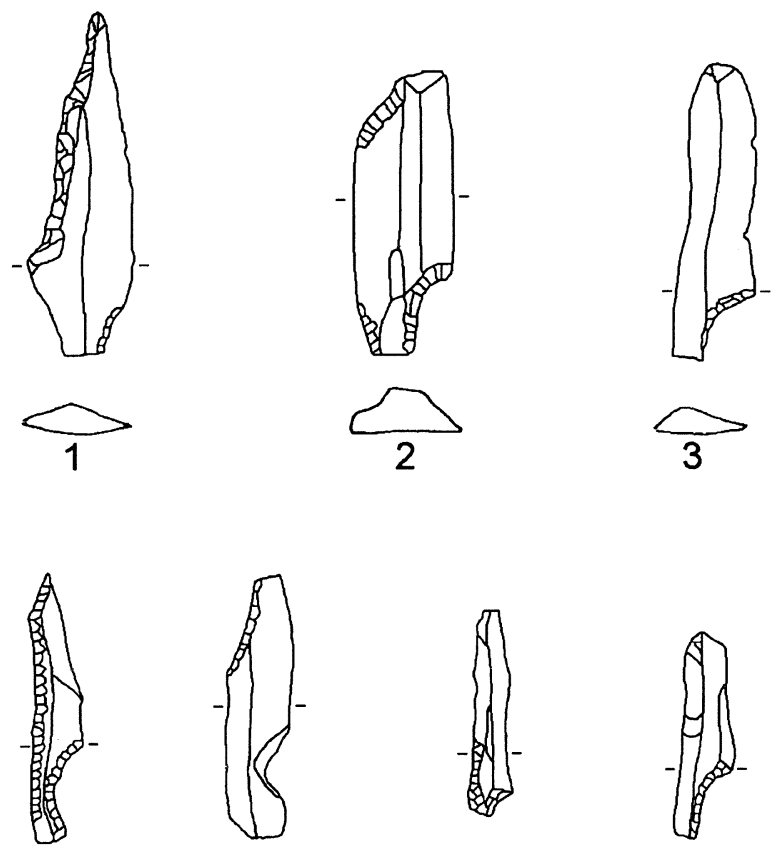

$\Delta$

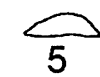

$\frac{\Omega}{6}$

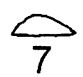

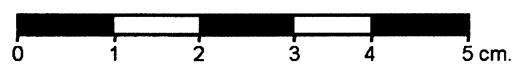

Fig. 5. Puntas de muesca de tipo mediterráneo en proceso de elaboración. La Cueva de Ambrosio (Vélez-Blanco, Almería): Solutrense Superior Evolucionado (Nivel II).

ños. Solo aparecen cinco puntas con una longitud total inferior a los $25 \mathrm{~mm}$. No obstante, hay que señalar que, en la mayoría de los casos, su incidencia no es excesiva; aunque lógicamente resta al proyectil estabilidad direccional y capacidad de penetración.

En cuanto al segundo accidente, la torsión, resulta difícil explicar por qué se eligen soportes con estas características morfológicas, casi similares a un golpe de buril. Aunque solo hay tres piezas, es evidente que dificultan un enmangue óptimo. La generación de estos soportes durante procesos de talla laminar es escasa y, casi se podría decir que fortuita.

Otra constante son los levantamientos previos a la extracción del soporte en el anverso del mismo (Fig. 3: C) ya sean extracciones o aristas, normalmente situadas en el eje longitudinal de

soporte o muy cerca de él. La presencia mayoritaria de estos atributos, junto con la casi ausencia total de córtex, indica que los soportes empleados en la fabricación de estos proyectiles se encuentran en una fase avanzada del proceso de reducción del núcleo. En su inmensa mayoría $(94,23 \%)$ aristas y extracciones son paralelas al eje longitudinal del proyectil y solo en 3 casos (Fig. 6: 1, 3 y 6) oblicuas. Esta dirección dominante es consecuencia de la talla laminar, ya sea ésta unidireccional o bidireccional.

Es difícil determinar si la elección de soportes con negativos de levantamientos previos es intencional o no. Lo cierto es que aristas y extracciones marcan el punto de inflexión hasta donde llega el retoque abrupto (Fig. 6: 14). En la mayoría de los casos, el grosor de la pieza en esta zona detiene el proceso de transformación. Esto se hace patente sobre todo en el filo del lado opuesto a la muesca y en la anchura que alcanza la misma. Sea predeterminada o no la elección de soportes con estas características, las líneas que delimitan estos levantamientos actúan como aristas-guía, haciendo que generalmente se consigan filos con un alto grado de rectitud.

\section{Morfología}

Aunque la punta de muesca es un objeto bien individualizado dentro del Paleolítico Superior europeo, existen numerosas categorías según las regiones, los yacimientos y las industrias que las contienen. Pero no es objeto de este trabajo agrupar las diferentes piezas en función de sus características morfológicas con el fin de realizar un estudio tipológico. Se trata de individualizar las formas que definen los distintos elementos del proyectil para jerarquizarlos y reagruparlos sobre bases tecnológicas y funcionales (cadena operativa de fabricación, experimentación, etc.).

En primer lugar, destaca la variedad formal en la silueta de la punta. Aparecen casi todas las combinaciones posibles entre el borde de la muesca y el opuesto a partir de las siguientes morfologías: recta, convexa, cóncava y sinuosa (Fig. 7: A). No obstante hay formas dominantes, como las rectas, y otras residuales. Tanto en los bordes cóncavos como en los convexos, las formas curvas no son muy pronunciadas. Los bordes sinuosos se corresponden por regla ge-ne- 

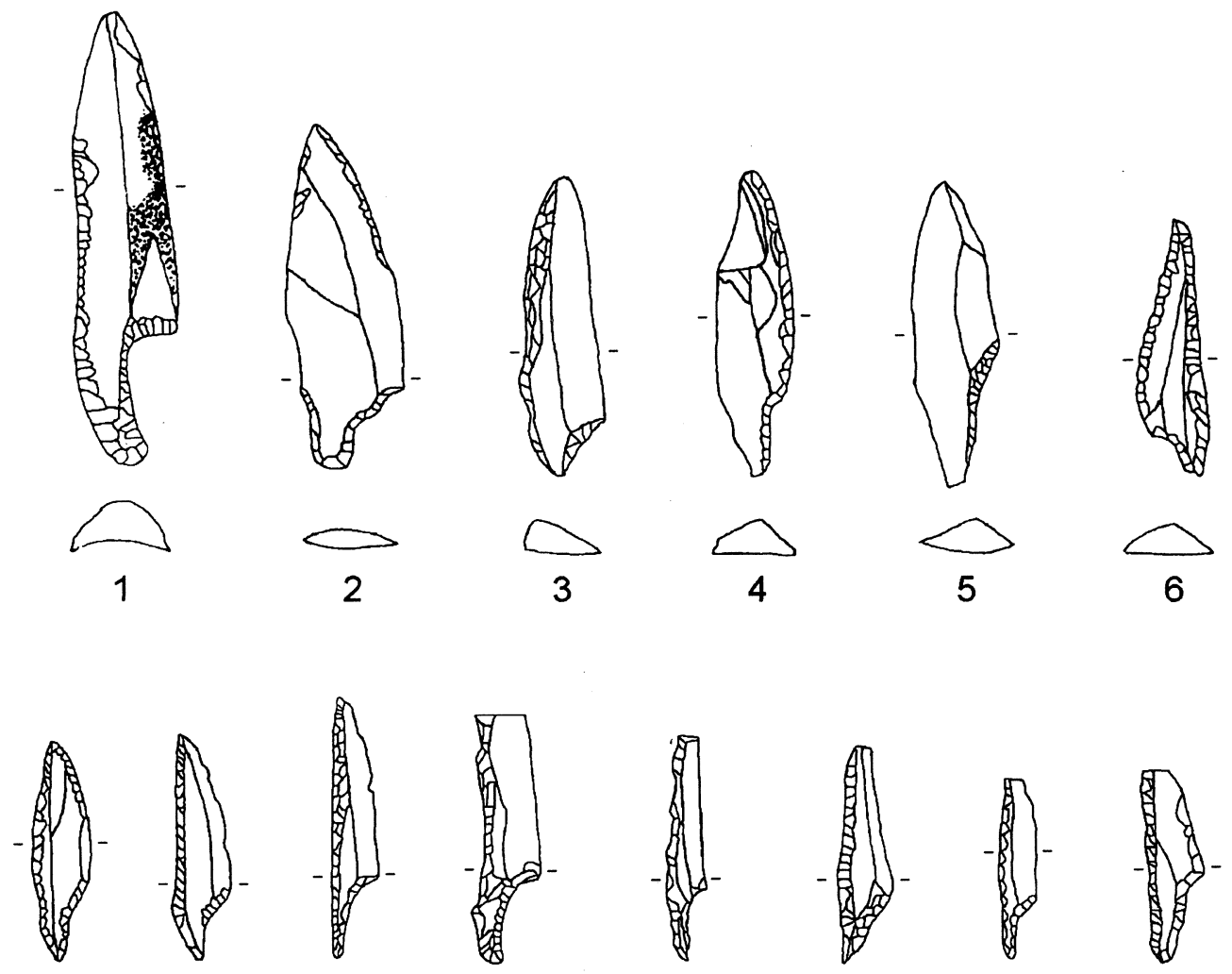

$\Rightarrow \quad \sigma_{8} \quad 0$

$\triangle$

$\Delta$

$\underset{12}{\infty}$

$\frac{0}{13}$

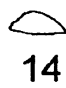
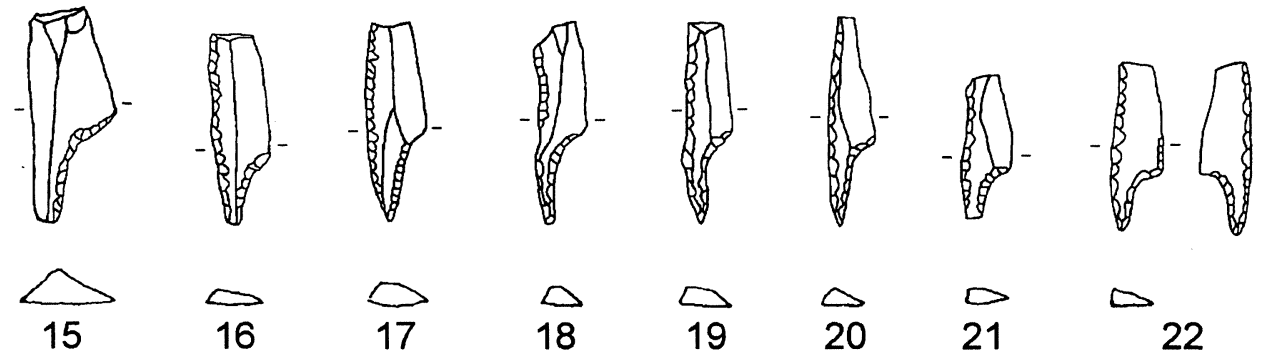

$\underset{18}{\Delta}$

$\underset{20}{20}$

21

22
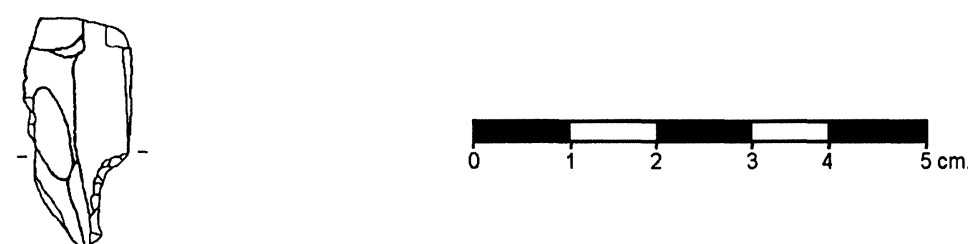

$$
\sum_{23 .}
$$

Fig. 6. Puntas de muesca de tipo mediterráneo. La Cueva de Ambrosio (Vélez-Blanco, Almería): Solutrense Superior Evolucionado (Nivel II).

T. P., 54, n. $^{\circ} 1,1997$ 
ral con filos retocados de forma irregular (Fig. 6: 11).

Las diferentes asociaciones morfológicas hacen aconsejable establecer subtipos o categorías dentro de la punta de muesca a partir de la variación formal y de las implicaciones funcionales que se derivan de la misma:

Subtipo A: Representan el 38,79\% de la muestra. Son puntas triangulares, alargadas, estrechas y delgadas (Fig. 6: 9, 15 y 19 y Fig. 4: 15). El borde situado en el lado de la muesca como el opuesto son rectilíneos. Son las más gráciles en su aspecto general. La muesca está bien diferenciada del fuste. El ángulo que forma el extremo distal oscila entre los $10^{\circ}$ y $20^{\circ}$, siendo la media aritmética de esta magnitud para toda la población de $20^{\circ}$. Son las más idóneas para la sujeción al astil y su capacidad de penetración es la más alta. Sus características generales, a expensas de estudios experimentales, la confirman como la morfología más idónea para la función de punta de proyectil ligera.

Subtipo B: Un segundo grupo, el 26,53\% del total, presenta el borde de la muesca ligeramente convexo y el opuesto rectilíneo (Fig. 6: 6 y 8 y Fig. 4: 2 y 7). No llegan a alcanzar el contorno triangular casi perfecto de las anteriores, con formas más redondeadas. En ocasiones la muesca está muy poco insinuada. El ángulo formado en el extremo apical puede alcanzar los $30^{\circ}$. En este tipo de proyectil la capacidad de penetración queda algo mermada, ya que, al tener en general ángulos mayores, la fuerza que se debe imprimir al disparo para obtener la misma efectividad es mayor que en el tipo anterior.

Subtipo C: El 12,24\% de la población corresponde a proyectiles con el borde de la muesca rectilíneo y el opuesto ligeramente convexo (Fig. 6: 1 y 23 y Fig. 4: 11 y 12). El ángulo de la punta oscila entre $\operatorname{los} 30^{\circ}$ y los $15^{\circ}$. Teóricamente, al igual que las del subtipo $\mathrm{D}$, presentarían mayores problemas para su enmangue al presentar el borde opuesto al filo de la muesca una ligera convexidad. En cuanto a su capacidad de penetración, ésta sería algo menor que las del subtipo anterior.

Subtipo D: El último grupo, $8,16 \%$, son puntas más rechonchas y anchas que las anteriores. Su contorno se inscribe en una ojiva, donde los bordes convergentes de la punta son convexos (Fig. 6: 2, 4, 5 y 7). El ángulo oscila entre los $25^{\circ}$ y $40^{\circ}$, siendo los valores máximos de la muestra.
Las carencias funcionales de este subtipo son las más evidentes tanto para el engaste como para la penetración. Sin embargo, si son lanzadas con la fuerza suficiente, pueden causar más daños al blanco debido a su volumen algo mayor.

El resto de la población de estudio $(2,04 \%)$ tienen características comunes a las anteriores. Pero, debido a su variabilidad morfológica, habría que agruparlas en numerosos subtipos con una o dos unidades. Aquí, la delineación de los bordes contempla formas cóncavas, convexas y sinuosas; aunque casi siempre uno de ellos es rectilíneo. Los ángulos que forman el extremo apical oscilan entre los $25^{\circ}$ y $35^{\circ}$. Por último, en el $12,24 \%$ de los casos, no ha sido posible establecer su morfología.

Respecto a las muescas (Fig. 7: B), dominan las triangulares (Fig. 6: 17) seguidas de las rectangulares (Fig. 6: 21). En ambos casos constituyen una prolongación del borde opuesto donde se sitúan y, en algunas ocasiones, éste se estrecha progresivamente hasta la base. Por último, algunos ejemplares tienen forma de coma (Fig. 4: 23). Esta sería una variante de la muesca triangular
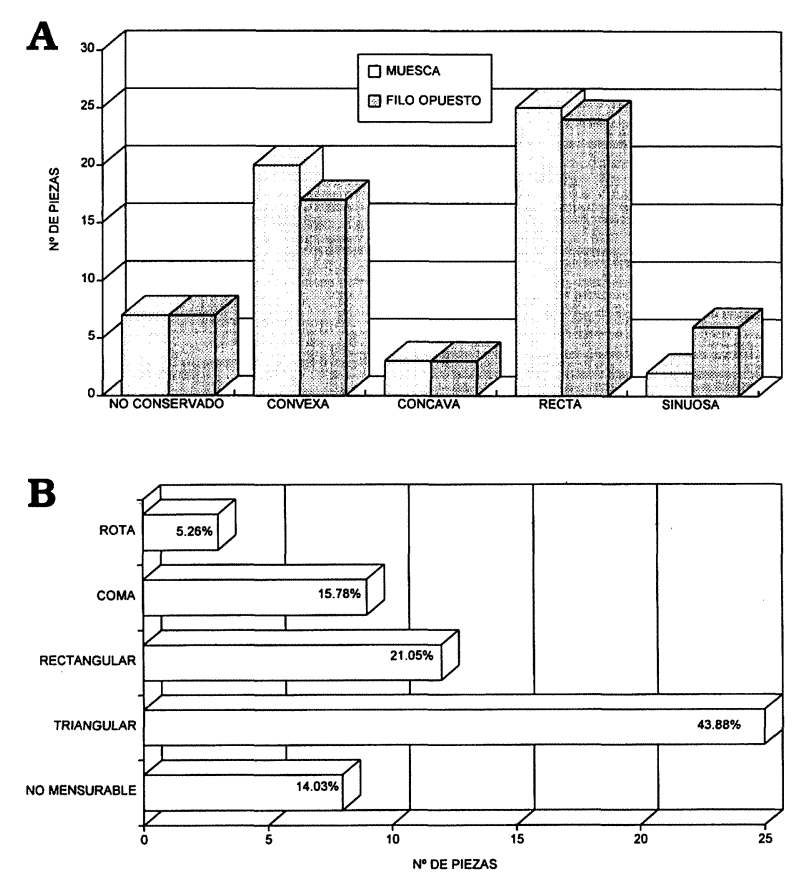

Fig. 7. Puntas de muesca de tipo mediterráneo del Solutrense Superior Evolucionado (Cueva Ambrosio, Vélez-Blanco, Almería). A: Delineación de los bordes; B: Morfología de la muesca. 
que, en lugar de ser recta, se curva hacia el eje longitudinal de la pieza, dándole un aspecto de gancho (Fig. 6: 1). Este mismo fenómeno se observa en las puntas de muesca del ámbito valenciano (Villaverde y Peña, 1981) y en las puntas de muesca solutrenses de retoque plano del tipo " $B$ " de la región francesa de la Dordoña (Geneste y Plisson, 1990). En el 89,47\% de los casos la muesca está orientada a la derecha, mientras que en sólo cuatro ejemplares la orientación es izquierda (Fig. 6: 6 y Fig. 4: 25-27). No se advierte ninguna diferencia substancial que las pueda alejar o diferenciar de los proyectiles con la muesca en el lado derecho. Parámetros tipométricos, tecnológicos y morfológicos no hacen pensar que no sean verdaderas puntas de muesca. La existencia de proyectiles con la muesca en el lado izquierdo puede responder a ventajas morfológicas intrínsecas en el soporte como fracturas angulosas, mayor grosor, etc.

La unión de la punta con la muesca en la zona de enmangue es en su inmensa mayoría $(94,33 \%)$ cóncava y en solo 3 casos forma un ángulo recto (Fig. 8: 14, 18 y 19). Este sería otro elemento de diferenciación entre la punta de muesca solutrense de retoque plano -donde mayoritariamente la unión entre estos dos elementos forma un ángulo recto- y la punta de muesca mediterránea.

\section{Procesos de fragmentación}

El número y localización de las fracturas que afectan a una pieza y, por lo tanto, a la morfología de los fragmentos obtenidos, constituyen criterios muy significativos desde el punto de vista funcional y tecnológico. En la muestra analizada sólo el $17,54 \%$ de los proyectiles están completos, el 70,18\% tienen una sola fractura y el $12,58 \%$ presenta dos fracturas. En la localización de las mismas los porcentajes hacen referencia al total de fracturas. La distribución de la frecuencia de fragmentación depende en gran medida de los sistemas de sujeción al astil. Si la punta está unida al astil solamente con materiales adhesivos, experimentalmente se ha comprobado que, o bien se despega en el momento del impacto o bien se fractura en el extremo distal. Si por el contrario el proyectil está firmemente fijado al astil (atado y pegado) en el momento de la colisión la punta no puede retroceder. Así, ésta se

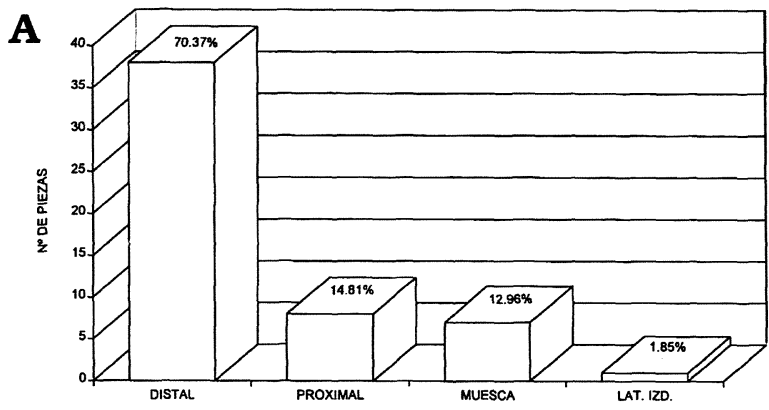

B

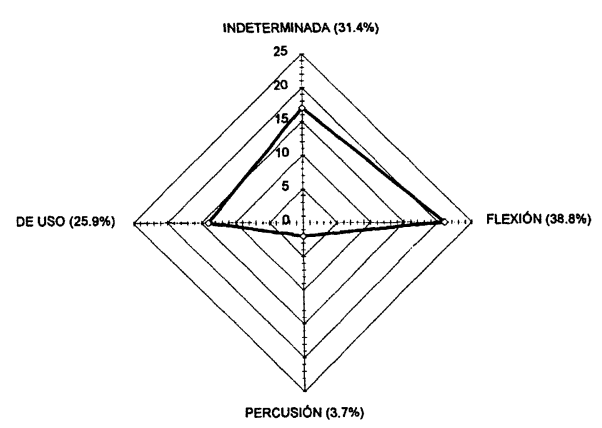

Fig. 8. Puntas de muesca de tipo mediterráneo del Solutrense Superior Evolucionado (Cueva de Ambrosio, Vélez-Blanco, Almería). A: Localización de fracturas; B: Tipos de fracturas.

rompe en diferentes fragmentos, con una elevada frecuencia de fracturas en la zona de enmangue o en la parte inmediatamente superior. Lógicamente en el registro arqueológico los fragmentos mesiales y distales serán mucho menos numerosos.

Excluidas las piezas no acabadas, el $12,19 \%$ son extremos distales mientras que el $39,02 \%$ corresponden a fracturas situadas en la zona de enmangue o muy próximas a ella (Fig. 8: A). Los datos parecen indicar que las puntas de muesca de La Cueva de Ambrosio fueron cuando menos atadas al astil. Esto explicaría la abundancia de los fragmentos proximales de las puntas de muesca, que quedarían unidos a los astiles.

Sin duda, para la tecnología desarrollada en este periodo era más fácil fabricar una punta de muesca que un astil con una rectitud, dureza y equilibrio direccional razonables. Entonces, parece lógico pensar que habría un interés importante en recuperar los astiles tanto de la pieza de caza como aquellos que no habían hecho blanco. Los extremos apicales llegarían al yacimiento alojados en los cuerpos de los animales cazados, bien porque se fracturara la punta durante la pe- 
netración o bien al intentar sacar el astil. Una vez desmontadas de los astiles serían arrojadas a las estructuras de combustión. Esta hipótesis ha sido ya planteada (Ripoll, 1988; Geneste y Plisson, 1990) y el material arqueológico parece confirmarla.

No es probable que los procesos de fragmentación hayan tenido lugar en el yacimiento. Por un lado, se da una ausencia total de uniones entre los fragmentos de los proyectiles. Además, algo más de la mitad de la población de estudio procede de la zona denominada "Microestratigrafía", una sucesión de estructuras de combustión perfectamente delimitadas que contienen el material arqueológico. Son compartimentos estanco que albergan los desechos industriales de un momento concreto o de un periodo relativamente corto. Por otro lado, un considerable número de fracturas son características de un uso como proyectil.

En cuanto a la causa de las fracturas (Fig. 8: B), los porcentajes siguen haciendo referencia al número total de las mismas. En su distribución sobresalen las fracturas por flexión, siguiendo la tónica general de los niveles solutrenses del yacimiento. Las fracturas características de un uso como proyectil son el $25,9 \%$. Su frecuencia entre los diferentes campos es la siguiente: lengüeta $(36 \%)$, burinoide $(36 \%)$, levantamiento en anverso $(14 \%)$ y levantamiento en anverso y reverso (14\%). Estos porcentajes son menores que en las puntas solutrenses de los yacimientos franceses de la Dordoña, donde se ha realizado un estudio similar. Aquí, las fracturas burinoides pueden alcanzar hasta el $13 \%$ del total y las fracturas en lengüeta hasta el 40\% (Geneste y Plisson, 1990). Esta ostensible diferencia puede responder a los distintos sistemas de propulsión, diferentes tipos de presas o una población de estudio mucho más numerosa en el caso francés, etc.

En las fracturas de tipo burinoide (Fig. 9: A), la fuerza que las produce es aplicada bien en un área relativamente pequeña y la fractura se encuentra cerca del área de contacto o bien la fuerza se reparte sobre una superficie relativamente grande y la fractura no se inicia necesariamente cerca de donde se origina la presión. En el momento del impacto la fuerza ejercida sobre el borde menos ancho de la punta es oblicua al eje longitudinal de la misma. Esto provoca un levantamiento transversal terminado en un escalón o un reflejado que afecta a una gran parte del borde de la pieza y en ocasiones tiene cierta profundi-

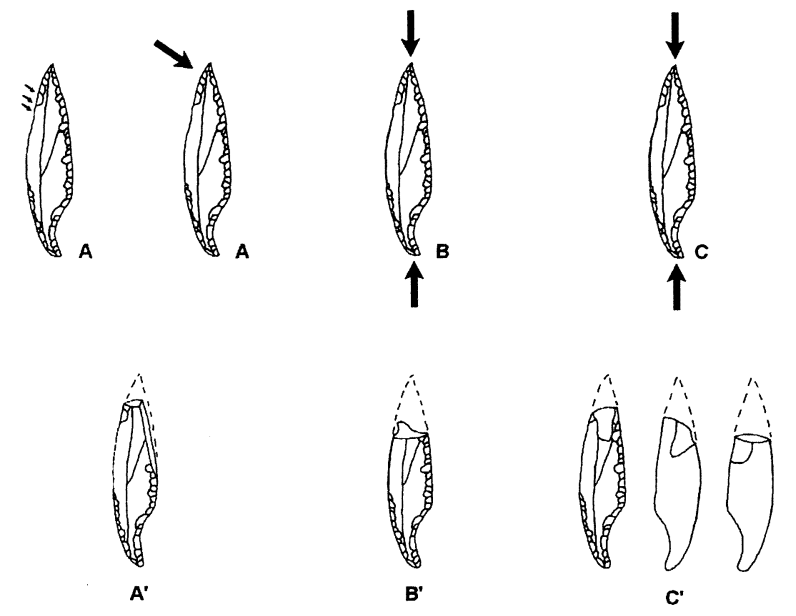

Fig. 9. Esquema de los tipos de fractura de uso como punta de proyectil y la intensidad y dirección de los vectores de fuerza que las generan. A: Tipo burinoide; B. En forma de lengüeta; C: Con levantamientos en anverso y/o reverso.

dad. La fuerza del impacto es dirigida hacia el interior del proyectil, donde se difumina, y después aflora a la superficie levantando una esquirla de dimensiones variables. Su nombre se debe a la gran semejanza que mantiene con los levantamientos burinoides.

Las fracturas en lengüeta (Fig. 9: B) se producen por la presión ejercida sobre los bordes anchos del proyectil por un impacto frontal con un objeto lo suficientemente duro como para no poder penetrarlo. La velocidad imprimida al proyectil hace que éste se rompa en dos, por flexión, y como consecuencia de la fuerza de la colisión se forma una lengüeta de considerables proporciones. Este proceso aparece sobre todo cuando el sistema de enmangue no permite un ligero retroceso de la punta sobre el astil. En realidad, se trata de una fractura por flexión que genera una lengüeta más o menos larga. Generalmente, tiene una amplitud de unos $2 \mathrm{~mm}$. Como parámetro para diferenciar las fracturas por flexión de las fracturas de uso, la lengüeta tendrá una amplitud mínima de $2 \mathrm{~mm}$. De esta forma, quedan descartadas las fracturas generadas por pisoteo, relleno sedimentario, intencionales y de fabricación.

Las fracturas con levantamientos en anverso y/o reverso (Fig. 9: C) son las más fácilmente identificables y probablemente las más características de un uso como proyectil. Experimentalmente se ha demostrado que los levantamientos 
en los bordes anchos del proyectil están condicionados por el tipo de fuerzas que los generan y de las que deriva su conexión con las fracturas en lengüeta. Cuando se produce la fractura por flexión debido a la presión en el lado ancho del proyectil -que puede o no generar una lengüeta característica de uso- el levantamiento sólo aparecerá en un lado ancho y será relativamente pequeño. Cuando las fuerzas corren paralelas a los bordes anchos los levantamientos pueden producirse en el anverso, en el reverso o en ambos y tendrán unas dimensiones considerables. Inmediatamente después de completarse la fractura, un grado considerable de energía cinética queda en el astil. Las dos piezas fracturadas continúan su penetración entrechocándose, a veces con gran fuerza. Como la orientación de la fuerza del astil, siempre perpendicular a las superficies fracturadas, es óptima para la aparición de retoques, los levantamientos producidos en las superficies anchas son frecuentes.

Las fracturas con levantamientos en ambos lados difícilmente pueden ocurrir por otro medio que no sea el de un uso como punta de proyectil, independientemente de sus dimensiones. Si la fractura solo tiene un levantamiento, es necesario una dimensión mínima para considerarla característica de uso. En el caso de las puntas ligeras de proyectil, como la punta de muesca mediterránea o la punta de aletas y pedúnculo, debe tener al menos $2 \mathrm{~mm}$. de longitud, mientras que para los proyectiles más grandes y pesados, como las hojas de laurel, los levantamientos deben ofrecer, al menos, una extensión de al menos $4 \mathrm{~mm}$.

\section{Tipometría}

En esta parte del estudio todas las medidas aparecen expresadas en milímetros. Siempre que ha sido posible, estos resultados se han comparado con los principales yacimientos del levante peninsular con estudios estadísticos similares (Fig. 1). Estas estaciones son Parpalló, Mallaetes y Barranc Blanc (Villaverde y Peña, 1981) y Chaves (Utrilla y Mazo, 1994). Este último yacimiento no se puede considerar estrictamente del ámbito levantino, aunque la aparición de puntas de muesca mediterránea en el interior peninsular y los recientes estudios de las relaciones entre Aragón y el litoral mediterráneo (Utrilla, 1992) durante la Prehistoria hace aconsejable su inclu- sión. Pero lamentablemente los análisis estadísticos de estas cuatro estaciones no contemplan todas las variantes del examen tipométrico de estas puntas.

En primer lugar, se analizan las magnitudes generales del proyectil (longitud, anchura y espesor) y sus correlaciones (Tablas 1 y 2). La longitud es la que presenta mayor variabilidad. Sin embargo, la diferencia entre los valores extremos de las medias aritméticas es menor de $2 \mathrm{~cm}$. $(16,1 \mathrm{~mm}$.). Este valor es mucho menor $(6 \mathrm{~mm}$.) si se excluyen las piezas de Chaves. Con respecto a la anchura, la diferencia entre el valores mínimo y máximo de las medias aritméticas es de $2,43 \mathrm{~mm}$. El espesor presenta una mayor modificación $(2,84 \mathrm{~mm}$.). Las variaciones son mínimas si se tiene en cuenta el número de ejemplares que forman la población. Así, parece que las técnicas de talla para la extracción de los soportes están encaminadas a una cierta homogeneización de la producción, salvando las distintas propiedades mecánicas de las materias primas empleadas.

El Índice de Alargamiento (I. Al.: longitud total/anchura máxima) se ha establecido en el $45,61 \%$ del total del conjunto, siendo su media aritmética de 5,91 (Tab. 1 y 2). Si se considera esta magnitud en aquellos proyectiles cuya longitud total no ha sido reconstruida, el I. Al. se sitúa en 5,07, una variación mínima. Así, las puntas de La Cueva de Ambrosio serían las más estrechas de todas (Tab. 3), seguidas por las de Chaves. En los proyectiles del ámbito valenciano, este índice se aproxima a los $3,5 \mathrm{~mm}$. En la

\begin{tabular}{|r|r|r|r|r|r|}
\hline \multicolumn{2}{|c|}{ L } & \multicolumn{2}{c|}{ A } & \multicolumn{2}{c|}{ I Ap } \\
\cline { 1 - 4 }$<21 \mathrm{~mm}$. & $10,71 \%$ & $<4 \mathrm{~mm}$. & $8,59 \%$ & $<4 \%$ & $7,69 \%$ \\
\hline $21-25 \mathrm{~mm}$. & $10,71 \%$ & $4-8 \mathrm{~mm}$. & $69,58 \%$ & $4-6 \%$ & $15,38 \%$ \\
\cline { 1 - 4 } $26-30 \mathrm{~mm}$. & $25,59 \%$ & $>8 \mathrm{~mm}$. & $21,73 \%$ & $7-9 \%$ & $46,17 \%$ \\
\cline { 1 - 4 } $31-35 \mathrm{~mm}$. & $21,43 \%$ & \multicolumn{2}{|c|}{$\mathrm{E}$} & $>9 \%$ & $30,76 \%$ \\
\cline { 1 - 3 } $36-40 \mathrm{~mm}$. & $14,18 \%$ & $<2 \mathrm{~mm}$. & $10,52 \%$ & & \\
\cline { 1 - 3 } $41-45 \mathrm{~mm}$. & $7,14 \%$ & $2-3 \mathrm{~mm}$. & $78,96 \%$ & & \\
\cline { 1 - 3 }$>45 \mathrm{~mm}$. & $7,14 \%$ & $>3 \mathrm{~mm}$. & $10,52 \%$ & & \\
\hline
\end{tabular}

Tabla 1. Tipometría de las puntas de muesca de la Cueva de Ambrosio (Vélez-Blanco, Almería) (I). L: Longitud total del proyectil; A: Anchura total del proyectil; E: Espesor total del proyectil; I Ap: Índice de aplanamiento. 


\begin{tabular}{|l|r|c|c|c|c|}
\hline \multicolumn{1}{|c|}{ YACIMIENTOS } & N. ${ }^{\circ}$ & \multicolumn{1}{c|}{ L } & A & E & I Al \\
\hline AMBROSIO & 57 & $\mathbf{3 1 , 0 3}$ & $\mathbf{6 , 7 7}$ & $\mathbf{2 , 3 6}$ & $\mathbf{5 , 9 1}$ \\
\hline PARPALLÓ $(3,75-4$ m.) & 50 & 28,1 & 8 & 3,2 & - \\
\hline PARPALLÓ (4-4,75 m.) & 443 & 28,6 & 8,6 & 3,4 & 3,32 \\
\hline PARPALLÓ (4,75-5,25 m.) & 113 & $\mathbf{3 3 , 9}$ & 8,5 & 4,3 & 3,85 \\
\hline MALLAETES & 38 & 32,8 & 9,2 & 3,8 & 3,67 \\
\hline BARRANC BLANC & 17 & 27,9 & $\mathbf{7 , 9}$ & 3,2 & 3,53 \\
\hline CHAVES & 14 & 44,2 & 8,5 & $\mathbf{2 , 8}$ & $\mathbf{5 , 3 4}$ \\
\hline
\end{tabular}

no contamos con datos para el resto de las estaciones, por lo que es imposible establecer ninguna correlación.

La longitud total de la punta (Tab. 4 y 5), se ha reconstruido en el $63,15 \%$ de la muestra. La media aritmética es de $24,23 \mathrm{~mm}$. Si solo se considera la población sin fracturas es de $28,16 \mathrm{~mm}$. Los valores van desde los $9 \mathrm{~mm}$. de longitud mínima hasta los $37 \mathrm{~mm}$. de longitud máxima. Si comparamos la media aritmética $(24,23 \mathrm{~mm}$.) con el resto de yacimientos, encontramos en Mallaetes -al igual que con la longitud total del proyectilla cifra más próxima con $24,3 \mathrm{~mm}$. En el resto de las estaciones, salvo en Chaves, la longitud de la punta en relación con la longitud total es bastante inferior si se correlaciona con Ambrosio o Mallaetes.

En el $17,54 \%$ de la población se han detectado

Cueva de Ambrosio, el $15,38 \%$ de las piezas son anchas -I. Al. menor de 4-. El 42,31\% del total de las piezas medibles corresponde a las puntas estrechas -I. Al. entre 4 y $6-$ y a las puntas muy estrechas -I. Al. mayor de 6-. Así, vemos que hay una inversión de los porcentajes del yacimiento con respecto a las tres estaciones levantinas.

El Índice de Aplanamiento (I. Al.: longitud total/espesor máximo), ha podido ser establecido en el 45,61\% de la población (Tab. 1 y 2). La media aritmética se sitúa en 15,62. Es decir, el grosor del proyectil representa el $6,4 \%$ de su longitud total. Los valores oscilan entre 8 y 39 : entre un $12,5 \%$ y un $2,56 \%$ de la longitud total del proyectil. En el $76,92 \%$ de la población, estos porcentajes se sitúan en valores superiores al $6 \%$ de la longitud total. Desgraciadamente,

\begin{tabular}{|l|c|c|c|}
\hline & $\begin{array}{c}\text { PUNTAS } \\
\text { ANCHAS }\end{array}$ & $\begin{array}{c}\text { PUNTAS } \\
\text { ESTRECHAS }\end{array}$ & $\begin{array}{c}\text { PUNTAS MUY } \\
\text { ESTRECHAS }\end{array}$ \\
\hline AMBROSIO & 15,38 & 42,31 & 42,31 \\
\hline PARPALLÓ & 71,13 & 27.97 & 0,9 \\
\hline MALLAETES & 45,45 & 54,55 & 0 \\
\hline $\begin{array}{l}\text { BARRANC } \\
\text { BLANC }\end{array}$ & 75 & 25 & 0 \\
\hline CHAVES & 8,33 & 66,67 & 25 \\
\hline
\end{tabular}

Tabla 3. Índice de Alargamiento (\%) de las puntas de muesca. melladuras en los filos de la punta, que no se asocian específicamente con ninguna morfología determinada de la misma. Aquellas aparecen en los proyectiles más grandes, a partir de $23 \mathrm{~mm}$. de longitud y $5 \mathrm{~mm}$. de anchura.

Si se parte de la hipótesis de un sistema de lanzamiento de estos proyectiles que acumulase en el astil una energía cinética similar, parece lógico

\begin{tabular}{|r|r|r|r|r|r|}
\hline \multicolumn{2}{|c|}{ LP } & \multicolumn{2}{c|}{ LM } & \multicolumn{2}{c|}{ AM } \\
\hline$<21 \mathrm{~mm}$. & $22,22 \%$ & $<5 \mathrm{~mm}$. & $13,9 \%$ & $<2 \%$ & $15,09 \%$ \\
\hline $20-24 \mathrm{~mm}$. & $27,79 \%$ & $5-6 \mathrm{~mm}$. & $16,2 \%$ & $2-4 \%$ & $60,39 \%$ \\
\hline $25-29 \mathrm{~mm}$. & $22,22 \%$ & $7-10 \mathrm{~mm}$. & $46,7 \%$ & $>4 \mathrm{~mm}$. & $24,52 \%$ \\
\hline $30-34 \mathrm{~mm}$. & $19,44 \%$ & $11-15 \mathrm{~mm}$. & $18,6 \%$ & \multicolumn{2}{|c|}{ A/AM } \\
\hline$>34 \mathrm{~mm}$. & $8,33 \%$ & $>15 \mathrm{~mm}$. & $4,6 \%$ & $25-45,4 \%$ & $42,85 \%$ \\
\hline \multicolumn{2}{|c|}{ L/LP } & \multicolumn{2}{|c|}{ L/LM } & $45,5-65,4 \%$ & $44,91 \%$ \\
\hline $60-69 \%$ & $27,27 \%$ & $12,5-21,4 \%$ & $46,16 \%$ & $65,5-85,5 \%$ & $12,24 \%$ \\
\hline $70-80 \%$ & $45,46 \%$ & $21,5-30,4 \%$ & $38,46 \%$ & \multicolumn{2}{|c|}{ E M } \\
\hline$>80 \%$ & $27,27 \%$ & $30,5-39,5 \%$ & $15,38 \%$ & $<1,5 \mathrm{~mm}$. & $18,86 \%$ \\
\hline \multicolumn{3}{|c}{} & & $1,5-2,5 \mathrm{~mm}$. & $66,05 \%$ \\
\cline { 3 - 6 } & & $>2,5 \mathrm{~mm}$. & $15,09 \%$ \\
\hline
\end{tabular}

Tabla 4. Tipometría de las puntas de muesca de la Cueva de Ambrosio (Vélez-Blanco, Almería) (II). LP: Longitud de la punta; L/LP: Longitud total del proyectil/longitud de la punta; LM: Longitud de la muesca; L/LM: Longitud total del proyectil/longitud de la muesca; AM: Anchura de la muesca; A/AM: Anchura total del proyectil/anchura de la muesca; EM: Espesor de la muesca.

T. P., 54, n. ${ }^{\circ} 1,1997$ 


\begin{tabular}{|l|r|r|r|c|}
\hline \multicolumn{1}{|c|}{ YACIMIENTOS } & \multicolumn{1}{c|}{ LP } & \multicolumn{1}{c|}{ LM } & \multicolumn{1}{c|}{ L/LM } & $\%$ \\
\hline AMBROSIO & $\mathbf{2 4 , 2 3}$ & $\mathbf{8 , 5 5}$ & $\mathbf{4 , 8 3}$ & $20,7 \%$ \\
\hline PARPALLÓ $(3,75-4 \mathrm{~m})$. & 21,1 & 7 & - & - \\
\hline PARPALLÓ $(4-4,75 \mathrm{~m})$. & 22,3 & $\mathbf{8 , 2}$ & $\mathbf{3 , 4 8}$ & $28,7 \%$ \\
\hline PARPALLÓ $(4,75-5,25 \mathrm{~m})$ & 20,6 & 12 & 2,85 & $35 \%$ \\
\hline MALLAETES & $\mathbf{2 4 , 3}$ & 9,4 & 3,13 & $31,9 \%$ \\
\hline BARRANC BLANC & 17,7 & 10,2 & 2,74 & $36,4 \%$ \\
\hline CHAVES & 29,8 & 14,3 & 3,1 & $32,2 \%$ \\
\hline
\end{tabular}

Tabla 5. Tipometría de las puntas de muesca (II): Media Aritmética. LP: Longitud de la punta; LM: Longitud de la muesca; L/LM: Longitud total del proyectil/longitud de la muesca; \%: Porcentaje de la longitud de la muesca en relación a la longitud total del proyectil.

pensar que la presencia de estos atributos se produce a partir de un volumen mínimo de materia. Por supuesto, aquí entran en juego otros factores, en donde el azar tiene un papel muy importante, como el rozamiento con las partes duras del animal (huesos, tendones, etc.) o con ramas, tierra, piedras y otros elementos del entorno, en caso de errar el tiro.

La relación entre la longitud total del proyectil y la longitud de la punta (L./L.P.) ha sido establecida en el 38,59\% de la población total (Tab. 4). La media aritmética se sitúa en 1,33. Aquí, los valores máximos y mínimos no presentan una gran amplitud (entre 1,14 y 1,65 ) y suponen entre el $86,5 \%$ y el $60,5 \%$ de la longitud total de la pieza. Se puede observar una correlación muy clara entre ambas medidas, pese a la gran amplitud entre los valores máximos y mínimos de la longitud total del proyectil. Además, en el $72,72 \%$ de la población la punta ocupa entre el $60 \%$ y el $80 \%$ del proyectil.

Estos datos implican una cierta estandarización en la producción. La variación en medidas absolutas puede ser más o menos elevada, pero se mantiene una proporción bastante coherente con respecto a la parte activa del útil, la punta. Además, como la longitud total de los proyectiles no sobrepasa los $50 \mathrm{~mm}$., es difícil suponer que el azar fuera el responsable de esta proporción. Desgraciadamente no hay datos similares para los yacimientos del área valenciana, por lo que de momento toda comparación a este respecto es inviable. Experimentalmente habrá que in- ferir si estas proporciones (Longitud Total/Longitud de la Punta) responden a condicionamientos funcionales, o si por el contrario están dentro de parámetros tecnológicos, culturales, etc.

La longitud de la muesca (Tablas 4 y 5) ha podido ser tomada en el 75,43\% de la población. En ningún caso ha sido posible reconstruirla cuando la muesca se encontraba fracturada. Al igual que sucedía con la longitud total de la pieza y de la punta, la de la muesca presenta una gran amplitud: entre 2 y $25 \mathrm{~mm}$. Sin embargo, en la mayoría de los ejemplares los valores están muy agrupados: en el 62,79\% la muesca se sitúa entre los 5 $\mathrm{mm}$. y los $10 \mathrm{~mm}$. La media aritmética es de 8,55 mm., equiparable a los 8,2 mm. del Parpalló (4 $4,75 \mathrm{~m}$.). En el resto de las estaciones es ligeramente superior: entre los $12 \mathrm{~mm}$. y los $9 \mathrm{~mm}$. Siguiendo la tónica general, en Chaves la longitud de la muesca se dispara hasta los $14,3 \mathrm{~mm}$. Dejándole al margen, los datos de los yacimientos estrictamente mediterráneos son también muy similares.

La relación entre la longitud del proyectil y de la muesca (L/L.M.) se ha establecido en el $45,61 \%$ de la población (Tab. 4 y 5). La media aritmética es 4,83 , es decir, un $20,7 \%$ de la longitud total del proyectil. Nuevamente, la proporción en los proyectiles que no tienen fracturas es muy similar, con una media aritmética de 4,41. Los valores máximos y mínimos oscilan entre 2,53 y 8 . Esto supone que la longitud de la muesca representa entre el $39,5 \%$ y el $12,5 \%$ de la longitud total del proyectil. A pesar de esta amplitud se observa una concentración en los valores más bajos. La proporción entre la longitud total y la de la muesca en La Cueva de Ambrosio es la más baja de los yacimientos del ámbito mediterráneo. El valor más cercano se sitúa en el Parpalló $(4-4,75 \mathrm{~m})$ con 3,48 , lo que significa que la muesca ocupa un $28,7 \%$ de la longitud total. Los otros yacimientos se disparan hasta el $36,4 \%$ en Barranc Blanc, el 35\% del tramo inferior del Parpalló y el 31,9 de Les Mallaetes.

Tradicionalmente, la relación L./L.M. era un elemento importante en la comparación de los distintos conjuntos industriales. Pero, por lo menos en el caso de La Cueva de Ambrosio, hay una mayor preocupación por conseguir una proporción estable entre la longitud total y la longitud de la punta (entre el $60 \%$ y el $80 \%$ ) que entre la primera y la de la muesca. Aunque en las series de ambos índices hay valores extremos, la prime-

T. P., 54, n. ${ }^{\circ} 1,1997$ 
ra relación mantiene parámetros más estables y agrupados. Como se corrobora más adelante con la anchura, las correlaciones de la zona de enmangue con las magnitudes totales del proyectil parecen tener un carácter secundario o, por lo menos, su papel funcional permite esta mayor variabilidad.

La anchura de la muesca ha sido determinada en el $92,98 \%$ de la población. La distancia entre los valores mínimos y máximos es menor que en el caso anterior aunque significativa, de 0,5 a 8 $\mathrm{mm}$. En la mayor parte de la muestra $(60,39 \%)$ la anchura de la muesca se sitúa entre los 2 y los 4 $\mathrm{mm}$ (Tab. 4). La media aritmética es de 3,42. Si la comparamos con la anchura máxima del proyectil $(6,77 \mathrm{~mm}$.), supone aproximadamente la mitad de la anchura total. Tanto en el caso de la anchura como en el espesor de la muesca, no hay datos publicados para los yacimientos de referencia.

La relación entre la anchura total y la anchura de la muesca se ha establecido en el 85,96\% de la población de estudio. El valor de este índice oscila entre 1,16 y 4 . Esto significa una grandísima amplitud de valores extremos que abarca desde el $85,5 \%$ hasta el $25 \%$ de la anchura máxima del proyectil (Tab. 4). La media aritmética se sitúa en 2,2, es decir, el 45,4\% de la anchura total. A pesar de la gran diferencia entre los valores máximos y mínimos, esta amplitud queda matizada por el hecho de que el 67,34\% del total se incluye en el intervalo del $25-50 \%$, que parece ser la proporción más buscada.

El espesor de la muesca ha podido ser medido en el $92,98 \%$ del conjunto. Los valores se sitúan entre los $0,5 \mathrm{~mm}$. y los $3,5 \mathrm{~mm}$. La inmensa mayoría de la población está situada en el intervalo de 1,5-2,5 mm. (Tab. 4). La media aritmética de esta magnitud $(1,88)$ es ligeramente inferior al espesor máximo del proyectil $(2,36)$ por la mayor amplitud de valores extremos de éste último. Como en ambos casos la mediana es la misma (2), se puede concluir que mayoritariamente el espesor de la muesca esta muy próximo o es coincidente con el espesor máximo.

\section{Procesos de fabricación}

Si bien la morfología y tipometría son datos importantes en el análisis del utillaje, no puede quedar relegado el hecho de que cada objeto es el resultado de un conjunto de procesos técnicos y tecnológicos. Así, el estudio de la "cadena operativa" empieza a ser habitual en bastantes trabajos sobre el estudio del material lítico de las sociedades cazadoras-recolectoras. Esta metodología sistematiza desde la selección y captación de materiales líticos hasta su transformación, uso, distribución y abandono. El objetivo de la individualización de las cadenas operativas de fabricación lítica es doble: la estructuración en etapas de los procesos reductivos y la identificación de los gestos técnicos e instrumentos empleados en cada una de ellas. Las diferentes propuestas para establecerlas (Bradley, 1975; Ericson, 1984; Karlin, 1991; Martínez y Alfonso, 1994) presentan pocas diferencias substanciales, por lo que se ha optado por adaptarlas a la problemática específica de las puntas de muesca mediterránea:

\section{ETAPA I: MODIFICACIÓN PRIMARIA}

Aprovisionamiento de la materia prima. Primer conjunto de actividades de modificación. (OBTENCIÓN DE NÚCLEOS)

\section{ETAPA II: MODIFICACIÓN SECUNDARIA}

Segundo conjunto de actividades de modificación.

(OBTENCIÓN DE SOPORTES)

\section{ETAPA III: ELABORACIÓN}

Tercer conjunto de actividades de modificación. (OBTENCIÓN DE ÚTILES)

\section{ETAPA IV: MONTAJE}

Primer conjunto de actividades para hacer factible el uso del útil.

(ENMANGUE)

ETAPA V: USO

Conjunto de actividades de uso.

Desecho, abandono o pérdida.

\section{ETAPA IIIa / IVa: MANTENIMIENTO}

Segundo conjunto de actividades para hacer factible el uso del útil.

(REAVIVADO, REPARACIÓN)

En cada una de ellas se generan un conjunto de productos característicos que serán desechados o bien pasarán a la siguiente etapa de la cadena operativa y, por último, formarán parte del registro arqueológico (Fig. 10). Sin embargo, todos estos productos no tienen que encontrarse nece- 
ETAPA I: MODIFICACIÓN PRIMARIA

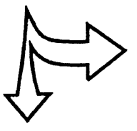

Abandono de la materia prima no adecuada, núcleos agotados o no aptos.

ETAPA II: MODIFICACIÓN SECUNDARIA

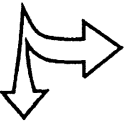

Abandono de los soportes de morfología inapropiada o fracturados durante su extracción.

ETAPA III: ELABORACIÓN

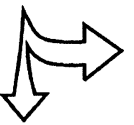

Abandono de útiles funcionalmente no adecuados o fracturados durante su elaboración.

ETAPA IV: MONTAJE

Abandono temporal de útiles morfológicamente no adecuados y pérdida.
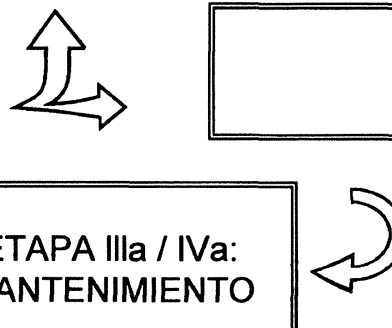

ETAPA V: USO

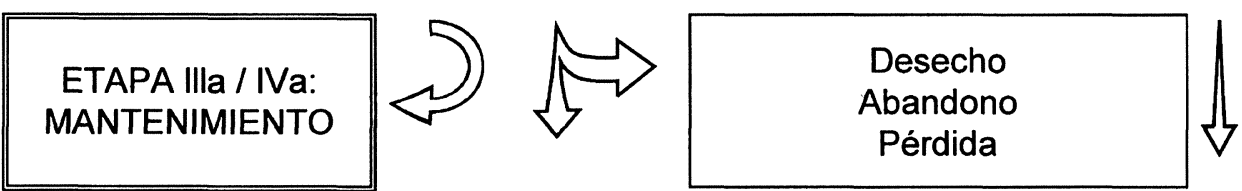

\section{DEPÓSITO ARQUEOLÓGICO}

Fig. 10. Secuencia de los procesos de transformación de la punta de muesca de tipo mediterráneo y su repercusión en el registro arqueológico.

T. P., 54, n. ${ }^{\circ} 1,1997$ 
sariamente en un mismo depósito arqueológico, ya que las actividades que integran la secuencia de reducción han podido o no llevarse a cabo en un mismo lugar. La presencia o ausencia de determinadas actividades marca las características técnicas del conjunto de estudio (Ericson, 1984).

El análisis industrial del Nivel II de La Cueva de Ambrosio, parece indicar la ausencia de la ETAPA I. De los 117.483 restos líticos recuperados del Solutrense Superior Evolucionado, únicamente el 3,19\% corresponden a piezas que tienen en más de las tres cuartas partes de su superficie presencia de córtex. Por el contrario las piezas que corresponden al tercer orden de extracción suponen el $81,39 \%$. Solo el $1,45 \%$ de las hojas y hojitas son soportes de primer orden, mientras que el $84,96 \%$ son de tercer orden. Por otro lado, los núcleos son solo el $0,05 \%$ de la industria.

Todos estos datos apuntan a que el primer conjunto de actividades de transformación no se producen en el yacimiento, sino, probablemente, en las propias áreas de captación o en sus proximidades. Al yacimiento llegarían los núcleos ya elaborados para la obtención de soportes y/o soportes ya preparados para la obtención del utillaje. Ambas opciones son posibles y no excluyentes.

En cuanto a la ETAPA III, la presencia de productos generados durante la talla laminar no es abrumadora: un $0,28 \%$ de aristas y semiaristas, un $0,08 \%$ de flancos de núcleo y un $0,07 \%$ de tabletas. Además, el 63,01\% del total de las piezas retocadas están realizadas sobre hojas y hojitas. Por lo tanto, la obtención de este tipo de soportes no va únicamente encaminada a la fabricación de puntas de muesca.

El análisis de los soportes y sus implicaciones tecnológicas y funcionales ya ha sido realizado a lo largo de este trabajo. El estudio experimental de las etapas que corresponden al montaje, uso y mantenimiento de este tipo de proyectiles está en curso de realización. Por ello, el análisis de la cadena operativa lítica de las puntas de muesca se centrará, por el momento, en la ETAPA III: elaboración. En ésta cobran gran importancia las piezas cuyo proceso de transformación no ha sido completado (Fig. 5).

Parece lógico pensar que, en los soportes laminares cuya modificación es parcial, la elaboración del proyectil empezaría por su elemento más delicado o frágil, es decir, la muesca (Fig. 5: 3 y 7). Debido a la cantidad de materia a eliminar para crearla y la anchura mínima que llega a alcanzar, las posibilidades de fracturar la hoja $u$ hojita son más altas que en el retoque de los bordes de la punta.

En 50 casos de la población total, la muesca es identificable. Sólo en un $4 \%$ del conjunto no se ha generado por un retoque sistemático y continuado (Tab. 6). Esto es debido a que el soporte presenta una fractura angulosa que dota al proyectil de la morfología adecuada sin necesidad de retoque (Fig. 4: 25), o bien la muesca tiene un único levantamiento -semejante a una muesca clactoniense- cuya elaboración no ha sido completada (Fig. 5: 5).

Lógicamente, la mayoría de las veces $(91,67 \%)$ el punto de enmangue también presenta retoque (Tab. 6). Su ausencia está asociada a dos factores: la muesca tampoco está retocada o el grosor del borde es muy fino, menor a $1 \mathrm{~mm}$. (Fig. 4: 19).

Una vez creada la muesca, el proceso de reducción del soporte puede tomar dos vías: bien se continúa retocando la zona de enmangue por el borde opuesto al filo de la muesca (Fig. 5: 2 y 6) o bien se comienza a retocar este borde por el extremo distal del proyectil para crear la punta (Fig. 5: 1 y 5). No se ha apreciado ninguna causa o pauta por la cual el proceso de transformación empiece por una u otra parte. Sin embargo, el retoque no necesariamente aparece en estas zonas. Así, en el borde opuesto a la muesca, el retoque está ausente del filo en el 26,53\% de la población (Tab. 6). En todos los casos esto sucede hasta el mismo borde de la punta, apareciendo el filo natural del soporte. En el filo opuesto al borde de la muesca, desde la altura del punto de enmangue hasta el extremo distal del proyectil (Tab. 6), el retoque está ausente en el 14,28\% de la muestra.

El proceso de reducción del soporte continúa por el borde del lado de la muesca, desde el punto de enmangue hasta el extremo distal de la punta (Tab. 6). El último paso en el proceso de elaboración es el retoque del extremo proximal del proyectil para adelgazar su espesor. Esto sólo se observa en el 14,64\% de la población. El grosor en esta zona oscila entre los 2 y los 3,5 mm., adaptándose a los valores medios de esta magnitud.

$\mathrm{El}$ retoque de las puntas de muesca en la mayoría de los casos no está destinado a crear un filo útil. Tanto en la muesca como en el punto de enmangue y en todo el borde del proyectil opuesto al lado de la muesca los levantamientos son irregu- 


\begin{tabular}{|c|c|c|c|c|c|c|c|}
\hline & $(\%)$ & A & B & $\mathrm{C}$ & D & E & F \\
\hline & AUSENTE & 4 & 8,33 & 26,35 & 14,28 & 62,22 & 85,36 \\
\hline 1 & Abrupto & 100 & 97,73 & 88,89 & 90,48 & 41,19 & 83,34 \\
\hline & Simple & - & 2,27 & 11,11 & 7,14 & 23,52 & - \\
\hline & Simple-abrupto & - & - & - & 2,38 & 32,29 & 16,66 \\
\hline 2 & Muy Marginal & 39,58 & 38,63 & 50 & 40,57 & 82,36 & 33,33 \\
\hline & Marginal & 60,42 & 61,37 & 50 & 59,53 & 17,64 & 66,67 \\
\hline 3 & Directo & 97,92 & 93,19 & 97,23 & 92,86 & 76,48 & 100 \\
\hline & Inverso & - & 2,27 & - & 2,38 & 11,76 & - \\
\hline & Alterno & - & - & - & - & - & - \\
\hline & Alternante & - & - & 2,27 & 4,76 & 11,76 & - \\
\hline & Bifacial & 2,08 & 4,54 & - & - & - & - \\
\hline 4 & Anchos & 100 & 97,73 & 97,23 & 100 & 88,24 & 50 \\
\hline & Alargados & - & 2,27 & 2,27 & - & 11,76 & 50 \\
\hline 5 & Sí & 47,61 & 34,09 & 58,34 & 47,61 & 76,48 & 83,34 \\
\hline & No & 52,39 & 65,91 & 41,66 & 52,39 & 23,52 & 16,66 \\
\hline 6 & Sí & 30,95 & 47,72 & 36,11 & 30,95 & 88,24 & 66,67 \\
\hline & No & 69,05 & 52,28 & 63,89 & 69,05 & 11,76 & 33,33 \\
\hline 7 & 1 & 21,42 & 68,19 & 38,88 & 21,42 & 70,59 & 100 \\
\hline & 2 & 73,82 & 31,81 & 58,35 & 73,82 & 29,1 & - \\
\hline & 3 & 4,76 & - & 2,77 & 4,76 & - & - \\
\hline 8 & $0-30 \%$ & - & - & - & 7,14 & 23,52 & - \\
\hline & $30-60 \%$ & - & 2,27 & 5,55 & 9,52 & 35,32 & - \\
\hline & $60-99 \%$ & 4,16 & 6,81 & 2,77 & 9,52 & 23,52 & - \\
\hline & $100 \%$ & 95,84 & 90,92 & 91,68 & 73,82 & 17,64 & 100 \\
\hline
\end{tabular}

Tabla 6. Análisis del retoque de las puntas de muesca de la Cueva de Ambrosio (Vélez-Blanco, Almería).

1: Modo; 2: Amplitud; 3: Dirección; 4: Relación longitud/anchura; 5: Regularidad del retoque; 6: Regularidad del filo; 7: Series de levantamientos encadenados y superpuestos; 8 : Grado de transformación.

A: Muesca; B: Punto de enmanque; C: Filo opuesto al borde de la muesca; D: Filo opuesto al borde de la muesca (punta); E: Filo del borde de la muesca (punta); F: Extremo proximal.

lares y el filo que crean no es uniforme. Aquí, parece confirmarse que el retoque busca destruir el filo natural para dar la forma deseada al soporte y para aplicar una mayor fuerza en el borde opuesto durante el corte o la punción.
Se mantiene constante la hegemonía de retoques abruptos y directos que afectan en gran parte o en su totalidad al borde de la pieza y con una intensidad de transformación importante, distinguiéndose generalmente -salvo en el punto de enmangue- hasta tres series de levantamientos encadenados. La ausencia de retoques inversos en este caso concreto, y su baja frecuencia en el conjunto de los proyectiles, muy probablemente es debido a la tendencia convexa de los productos laminares, que los hacen más vulnerables a las fracturas si la fuerza es ejercida desde el anverso.

Sin embargo, en el filo de la punta situado en el lado de la muesca la homogeneidad y uniformidad de los datos es evidente. Hay un predominio de retoques muy marginales, directos, regulares, que generan un filo uniforme mediante dos series de levantamientos encadenados y que afectan a menos de los dos tercios de la longitud total del borde (entre el $70 \%$ y el $80 \%$ del total de las piezas con retoque en esta zona). Además, en más de la mitad de la población no se produce ningún tipo de transformación.

La observación directa de la muestra de estudio hace pensar que la finalidad del retoque en este borde es crear un filo útil, regularizando su morfología y aumentando su capacidad de corte $\mathrm{y}$, por tanto, de penetración. Por ello, la intensidad de transformación es menor y selectiva: solo se aplica en aquellas zonas que la necesitan. El predominio del retoque simple y simple-abrupto, de forma conjunta, sobre los abruptos refuerza esta hipótesis. La formación de un borde mediante retoques abruptos a partir de un soporte con un filo natural y por tanto de escasísimo grosor necesita de varias series de levantamientos que aquí no aparecen. Por otro lado, en las otras zonas de la pieza la presencia de este tipo de retoques, simple y simple-abrupto, está en la mayoría de las ocasiones asociado a una o dos series de levantamientos.

\section{CONCLUSIONES}

Del estudio tecnológico y morfométrico de la punta de muesca mediterránea se desprende, en primer lugar, un gran aprovechamiento de las características que ofrece el soporte. Tanto aristas como extracciones delimitan su morfología y el grado de transformación. La presencia de filos naturales permite crear frentes activos con 
muy poca elaboración. La longitud, anchura y espesor de las hojas y hojitas marcan perfectamente la distribución de los distintos elementos que conforman el proyectil. Cuando aparecen ejemplares que se apartan de los parámetros generales, la mayoría de las veces es debido a las ventajas intrínsecas que ofrecen determinados soportes $\mathrm{y}$, en menor medida, para salvar sus carencias morfológicas que repercutirían negativamente en su rendimiento funcional. Las ventajas que presentan los soportes laminares, en relación a sus características tecnológicas, permite la existencia de una variación formal relativamente importante. Además, si bien la talla laminar implica una cierta estandarización en la producción, la fractura de los materiales quebradizos como el sílex genera una inevitable diversidad en el formato de los soportes. Sin embargo, esta variabilidad queda matizada por las asociaciones morfológicas con una preponderancia de siluetas rectilíneas, como queda reflejado en los subtipos establecidos.

Un fenómeno similar se constata en los valores absolutos de las magnitudes del proyectil. Las dimensiones volumétricas de la punta de muesca son también de una gran variabilidad. Sin embargo, las proporciones que guardan los diferentes elementos entre sí mantienen una gran homogeneidad. Así, en más del $72 \%$ de la población la punta supone entre el 70 y el $80 \%$ de la longitud total del proyectil y, en más del $84 \%$ del total, la muesca ocupa entre el 12,5 y el $21,4 \%$. La anchura de la muesca, en más del $67 \%$ de los casos, abarca entre el $25 \%$ y el $50 \%$ de la total. Estas magnitudes son, en líneas generales, similares al resto de los yacimientos del núcleo valenciano, exceptuando la relación entre la longitud y la anchura totales. Aquí, se produce una inversión de valores, siendo las puntas de muesca de Ambrosio mucho más estrechas. En el caso de Chaves, los proyectiles se alejan de las concepciones volumétricas de las puntas de muesca del ámbito mediterráneo peninsular. El desarrollo técnico y morfológico responde a la punta de muesca mediterránea, pero su tipometría está mucho más cercana de la punta de muesca solutrense de retoque plano de la cornisa cantábrica.

El retoque mayoritariamente tendría como objetivo dar forma a la pieza y no crear un filo útil. Sólo el situado en el mismo lado de la muesca-selectivo y con un escaso grado e intensidad de transformación del soporte- se encaminaría a crear un filo activo, regularizando su morfología y aumentado su capacidad de corte y, por tanto, de penetración. Estas características del retoque, junto con las del soporte, posibilitan en gran medida la uniformidad tipométrica de la población.

La homogeneidad que muestran las características técnicas del soporte y el aprovechamiento intensivo de sus ventajas intrínsecas, la proporción de las diferentes partes del proyectil y la repetición sistemática de las diferentes pautas que definen el retoque sugieren el desarrollo de un mismo esquema técnico para la fabricación de la punta de muesca mediterránea que tiene como base un solo patrón de trabajo. Es decir, se podría hablar de una producción con un alto grado de estandarización, teniendo siempre presente el marco cronológico en que estos procesos se desarrollan. Se fabrican proyectiles de diferentes tamaños para astiles de distintas medidas, pero que responden a un mismo paradigma. El siguiente paso será intentar averiguar si este esquema técnico responde a motivaciones culturales, funcionales o ambas.

Por último, este estudio aporta datos para abordar algunas cuestiones funcionales. Tanto la anchura como el espesor del punto de enmangue coinciden la mayoría de las veces con los valores máximos del proyectil. Asimismo, el retoque busca dar la forma deseada a esta zona. Es decir, no parece haber un tratamiento especial que la diferencie del resto de la muesca. Por otro lado, las fracturas situadas de 3 a $5 \mathrm{~mm}$. por encima de la muesca son muy frecuentes. Además, teniendo en cuenta la longitud de la misma, con una media aritmética de $8,55 \mathrm{~mm}$., parece lógico pensar que la punta no quedaría embutida en el astil desde la muesca, sino unos milímetros después de la misma. Un enmangue inferior a un centímetro no es lo bastante sólido para asegurar una buena sujeción.

La anchura total del proyectil, con una media aritmética de 7,9 $\mathrm{mm}$. y unos valores que oscilan entre los 15 y los $2 \mathrm{~mm}$., marcaría el límite del diámetro máximo que alcanzaría el astil. Este presentaría en su extremo distal un cajeado paralelo a su eje longitudinal donde se alojaría el proyectil. También, no hay que descartar una morfología cónica del extremo distal para adaptarse mejor a las dimensiones de la punta. La muesca permitiría la fijación de la punta al astil mediante fibras vegetales eliminando de esta zona durante la penetración cualquier tipo de ro- 


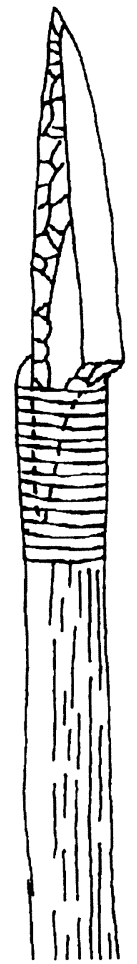

Fig. 11. Hipótesis de enmangue de la punta de muesca de tipo mediterráneo.

zamiento (Fig. 11). La presencia en el borde opuesto de un retoque abrupto con varias series de levantamientos crea una superficie rugosa que favorece su sujeción mediante elementos adhesivos. Esto permite que el proyectil quede fijado firmemente. Así, cuando la punta se encuentra con un objeto que le impide seguir penetrando, no puede retroceder sobre el astil, fracturándose al nivel del enmangue. Esto explicaría la alta frecuencia de fracturas a esta altura.

\section{BIBLIOGRAFÍA}

BietTi, A. (1980): “Analyse typologique et tipométrique de quelques outiles à cran des gisements epigravettiens du Sud-est de l'Italie: Paglicci (Foggia) et Turisano (Lecce)". Quaternaria, XXII: 243-273.

BRADLEY, B. (1975): "Lithic reduction sequences: a glosary and discussion". En E. Swanson (ed.): Lithic technology. Making and using stone tools. Chicago: 5-13.

Broglio, A.; Chelidonio, G. y Longo, L. (1993): “Analyse morphologique et fonctionnelle des pointes à cran de l'Épigravettien ancien. Traces et fonction: les ges- tes retrouvés". En Colloque International de Liège. Etudes et Recherches Archéologiques de l'Université de Liège, 50: 31-39. Liège.

ERICSON, J. (1984): "Toward the analysis of lithic production systems". En J. Ericson y B. Purdy (eds.), Prehistoric quarries and lithic production. Cambridge University Press. Cambridge: 1-9.

ForTEA, J. (1973): Los complejos microlaminares y geométricos del Epipáleolítico Mediterráneo Español. Memorias del Seminario de Prehistoria y Arqueología, 4. Universidad de Salamanca. Salamanca.

Fullola, J.M. a (1976): "Revisión de la industria lítica de los niveles solutrenses de la Cueva del Parpalló". Pyrenae, XII: 35-72. Barcelona.

Geneste, J. M. y Plisson, H. (1986): “Le Solutréen de la Grotte de Combe Sauniére (Dordogne). Première approche paléthnologique". Gallia Préhistorique, 29: 9-27. París.

- (1990): "Téchnologie fonctionnelle des pointes à cran solutréennes: l'apport des nouvelles donnees de la grotte de Combe Saunière (Dordogne)". En J. Kozlowski (org.): Feuilles de pierre. Les industries à points foliacées du Paléolithique Supérieur Européen. Actes du Colloque de Cracovie, 1989. Etudes et Recherches Archéologiques de l'Université de Liège, 42: 293-320. Liège.

KarLin, C. (1991): "Connaissances et savoir-faire: comment analyser un proces téchnique en Préhistoire: Introduction". En R. Mora, X. Terradas, A. Parpal y C. Plana (eds.): Tecnología y cadenas operativas líticas. Treballs d'Arqueologia, 1: 99-124. Barcelona.

LENOIR, M. (1975): “Observations sur les pointes à cran magdaleniénnes dans les gisements de l'abri Faustin, commune de Cessac (Gironde) et de la Pigue, commune de Daignac (Gironde)". Bulletin de la Société Préhistorique Française, 72: 107-112. París.

PlA, E. (1978): "Prehistoria y Protohistoria". En Iniciación a la historia de Oliva. Ayuntamiento de Oliva. Oliva.

MarTí, B. y GIL, J. (1978): "Perlas y aletas de glóbulos del Cau del Raboser". Archivo de Prehistoria Levantina, XV: 47-68. Valencia.

Martínez, G. y Afonso, J. (1994): "Sobre el concepto de producción lítica". En T. Orozco y X. Terradas (eds.): $1^{a}$ Reunión de trabajo sobre aprovisionamiento de recursos líticos en la Prehistoria (Valencia, 1984). Dossier de Trabajo. Valencia: 1-15.

Merino, J.M.a (1994): “Tipología Lítica”. Munibe (Antropologia-Arkeologia). Suplemento, 9. Sociedad de Ciencias Aranzadi. San Sebastián, 3. a edición (corregida y aumentada).

Moure, J.A. (1969): “Comentarios sobre el uso en la lengua castellana de la léxico-tipología del Paleolítico Superior de acuerdo con el sistema Sonneville-Bordes y Perrot". Boletín del Seminario de Arte y Arqueología, XXXIV-XXXV: 275-288. Valladolid.

OnORATINI, G. (1978): “Un nouveau type de pointe à

T. P., 54, n. $^{\circ} 1,1997$ 
cran: pointe de la Bouverie dans le complexe general des pointes à cran". Bulletin de la Société Préhistorique Française, 75: 522-542.

Plisson, H. y Geneste, M. (1989): “Analyse téchnologique des pointes à cran solutréennes de Placard (Charente), du Fourneau du Diable, du Pech de la Boissiére et de Combe Saunière (Dordogne)". Paléo, 1: 65-106.

Rasilla, M. de la (1981): "Metodología de trabajo para el estudio de las puntas solutrenses". En Primeras Jornadas de Metodología de Investigación Prehistórica. Soria, 1981. Ministerio de Cultura. Madrid: 131-144.

Ripoll, E. (1960-1961): "Excavaciones en Cueva de Ambrosio (Vélez Blanco, Almería). Campañas 1958 y 1960". Ampurias, XXIl-XXIII: 31-45.

Ripoll, S. (1988): El Solutrense de la Cueva de Ambrosio (Almería, Spain) y su posición cronoestratigráfi-

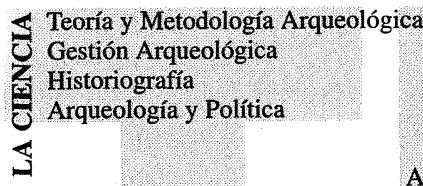

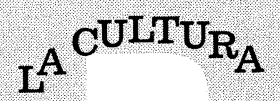

Arqueología Prehistórica y Protohistórica Paleolítico Neolítico Calcolítico

Edad del Bronce Edad del Hierro

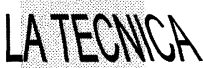

Datación absoluta

Arqueología analítica

Arqueometalurgia

Tecnología experimental

Trabajos de Prehistoria es la revista de consulta imprescindible para todos aquellos interesados en conocer el estado de la cuestión sobre el rico patrimonio arqueológico de la Prehistoria y Protohistoria de la Península lbérica. Sus páginas reflejan tendencias punteras de su especialidad, por lo que figura en los más significativos repertorios bibliográficos nacionales e internacionales. tura. Madrid. ca en el Mediterráneo Occidental. B.A.R. International Series, 462. Oxford.

STRAus, L. (1983): El solutrense vasco-cantábrico. Una nueva perspectiva. Monografías del Centro de Investigación y Museo de Altamira, 10. Ministerio de Cul-

UTRILlA, P. (1992): “Aragón/Litoral mediterráneo. Relaciones durante el Paleolítico". En P. Utrilla (coord.): Homenaje a Juan Maluquer de Motes. Aragón/Litoral Mediterráneo: Intercambios culturales durante la Prehistoria. Instituto Fernando el Católico. Zaragoza: 9-35.

Utrilla, P. y Mazo, C. (1994): "El Solutrense en el Valle Medio del Ebro". Férvedes, 1: 89-104.

Villaverde, V. y Peña, J.L. (1981): Piezas con escotadura del Paleolítico Superior valenciano. S.I.P. Serie de Trabajos Varios, 69. Valencia.

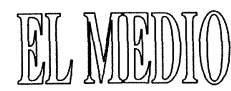

Arqueobotánica Arqueozoología Arqueología del Paisaje

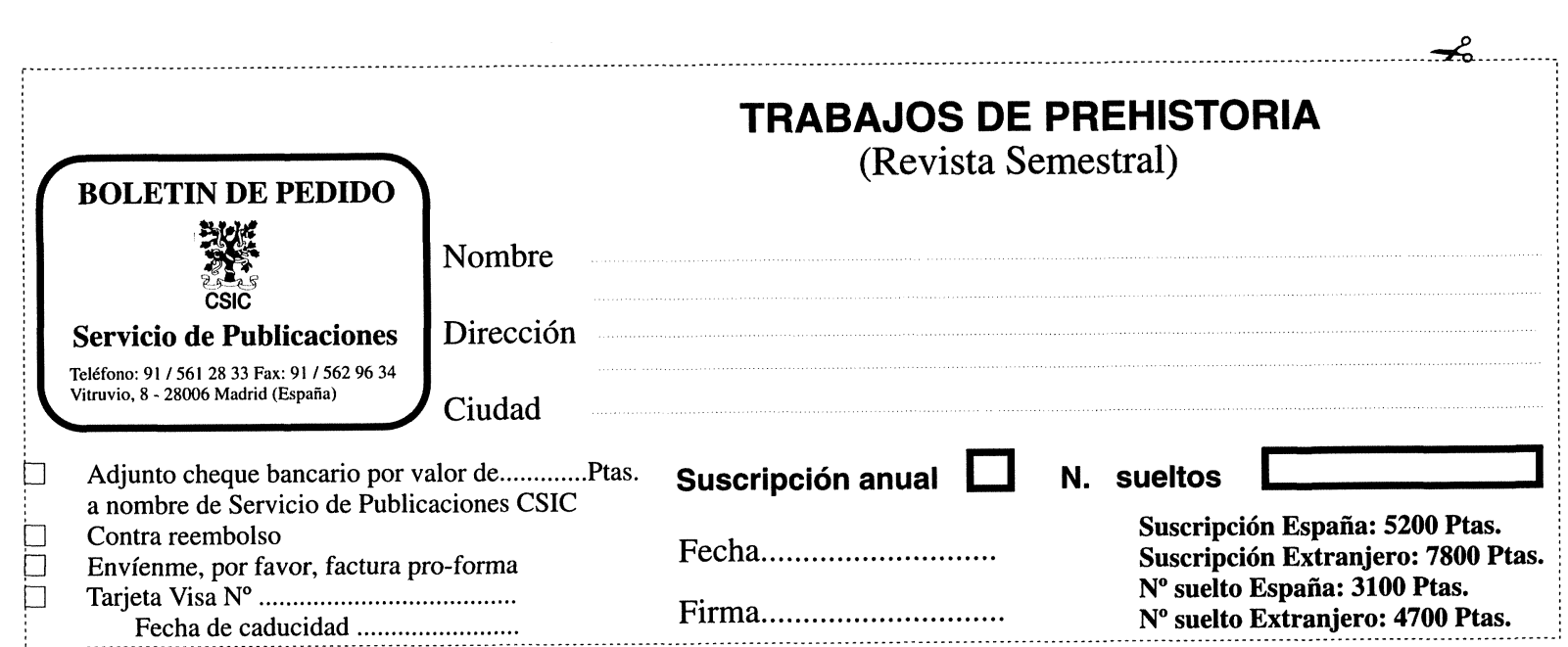

T. P., 54, n. $^{\circ} 1,1997$ 